\title{
Actores no estatales y externalización de las funciones militares en los conflictos armados: los contratistas privados ante el derecho internacional humanitario
}

Fecha de recepción: 22 de enero de 2014

Fecha de aceptación: 9 de octubre de 2014

Doi: http://dx.doi.org/10.12804/acdi8.1.2015.02

Julio Jorge Urbina*

Resumen: La proliferación de actores no estatales en los conflictos armados contemporáneos constituye un desafío para la aplicación del derecho internacional humanitario. Entre estos actores, los contratistas privados han adquirido un especial protagonismo por las tareas que llevan a cabo y por el personal desplegado en zonas de conflicto, hasta el punto de que su presencia se ha hecho prácticamente indispensable. Pero este protagonismo está planteando, entre otros problemas, la necesidad de definir el régimen

* Doctor en Derecho. Profesor titular de Derecho Internacional Público; director del Departamento de Derecho Público y Teoría del Estado; coordinador del Máster Universitario en Estudios Internacionales de la Universidad de Santiago de Compostela. Ha colaborado con el Centro de Estudios de Derecho Internacional Humanitario y el Comité Internacional de la Cruz Roja en la elaboración de la práctica española para el proyecto de Derecho Internacional Humanitario Consuetudinario y con el Grupo de Trabajo de las Naciones Unidas sobre Utilización de Mercenarios en relación con un proyecto de convención sobre empresas militares y de seguridad privada. Dirección postal: Área de Derecho Internacional Público, Facultad de Derecho, Universidad de Santiago de Compostela. Campus Vida. 15782-Santiago de Compostela (España).Correo electrónico: julio.jorge@usc.es

Para citar este artículo: Jorge Urbina, Julio. "Actores no estatales y externalización de las funciones militares en los conflictos armados: los contratistas privados ante el derecho internacional humanitario", ACDI - Anuario Colombiano de Derecho Internacional, 2015, 8, pp. 41-85. Doi: http://dx.doi.org/10.12804/acdi8.1.2015.02 
jurídico al que están sometidas estas empresas y su personal, para acabar así con la incertidumbre jurídica que rodea sus actividades. Esta situación ha dado lugar en la práctica a que se hayan beneficiado de una impunidad de facto a causa de las dificultades que surgen para su persecución en los casos de crímenes cometidos durante la prestación de sus servicios. Por ello, se debe insistir en que no existe ningún vacío legal en torno a estas empresas, aunque por el momento no existan normas específicas que regulen sus actividades. En efecto, el derecho internacional humanitario proporciona el marco jurídico adecuado para reglamentar las tareas que llevan a cabo estas empresas en los conflictos armados. Aunque el ius in bello no regula específicamente las compañías militares y de seguridad privadas, ni el estatuto de su personal, contiene reglas y principios que delimitan los derechos y obligaciones de sus empleados, especialmente cuando presten servicios armados, y definen el alcance su responsabilidad. Por eso, estas empresas deben adoptar medidas para asegurar el respeto de estas normas, pues, en caso contrario, incurrirán en responsabilidad, que se extiende a los gestores, directivos y administradores.

Palabras clave: derecho internacional humanitario, actores no estales, contratistas privados, cláusula Martens, responsabilidad del superior jerárquico.

Non-state Actors and Outsourcing of Military Functions in Armed Conflict: Private Contractors under International Humanitarian Law

Abstract: The proliferation of non-state actors in contemporary armed conflicts is a challenge for the implementation of international humanitarian law. Among these actors, private contractors have taken on a special role for the tasks performed and the personnel deployed in conflict areas, to the extent that their presence has become almost indispensable. But this prominence is posing, among other problems, the need to define the legal regime to which they subject these companies and their personnel in order to end the legal uncertainty surrounding their activities. This situation has led in practice to have benefited from de facto impunity because of the difficulties for prosecution in cases of crimes committed during the provision of their services. Therefore, we must insist that there is no legal vacuum around these companies although at present there are no specific rules governing its activities. Indeed, international humanitarian law provides the appropriate legal framework to regulate the tasks carried out by these companies in ar- 
med conflicts. Although ius in bello not specifically regulate private military and security companies, nor the status of their personnel, contains rules and principles that define the rights and obligations of their employees, especially when providing armed services, and define the scope of their responsibility. Therefore, these companies must take steps to ensure compliance with these rules, because otherwise incur responsibility that extends to managers, directors and administrators.

Key words: international humanitarian law, non-state actors, private contractors, Martens clause, command responsibility.

Atores não estatais e terceirização das funções militares nos conflitos armados: os empreitados privados ante o Direito Internacional Humanitário

Resumo: A proliferação de atores não estatais nos conflitos armados contemporâneos constitui um desafio para a aplicação do Direito Internacional Humanitário. Entre estes atores, os empreitados privados têm adquirido um especial protagonismo pelas tarefas que levam a cabo e pelo pessoal dispersado em zonas de conflitos, até o ponto que sua presença se tem feito praticamente indispensável. Mas este protagonismo está exposto, entre outros problemas, a necessidade de definir o regime jurídico ao que estão submetidas estas empresas e seu pessoal para acabar assim com a incerteza jurídica que rodea suas atividades. Esta situação tem ocasionado na prática a que se tenham beneficiado de uma impunidade de facto a causa das dificuldades que surgem para sua persecução nos casos de crimes cometidos durante a apresentação de seus serviços. Por isso, deve-se insistir em que não existe nenhum vazio legal em torno a estas empresas, ainda que pelo momento não existam normas específicas que regulem suas atividades. Em efeito, o Direito Internacional Humanitário proporciona o marco jurídico adequado para regulamentar as tarefas que levam a cabo estas empresas nos conflitos armados. Ainda que o ius in bello não regula especificamente as companhias militares e segurança privada, nem o estatuto de seu pessoal, contém regras e princípios que delimitam os direitos e obrigações de seus empregados, especialmente quando prestem serviços armados, e definem o alcance de sua responsabilidade. Por isso, estas empresas devem adotar medidas para assegurar o respeito destas normas, pois no caso contrário incorrerão em responsabilidade, que se estende aos gestores, diretivos e administradores. 
Palavras-chave: Direito internacional humanitário, atores não estatais, empreitados privados, cláusula Martens, responsabilidade do superior hierárquico.

\section{Consideraciones generales}

El derecho internacional humanitario se ha caracterizado a lo largo de toda su evolución por una incesante interacción con el medio social en el que se desenvuelven sus reglas. Al estar dirigido a ser aplicado en un entorno tan complejo como los conflictos armados, es inevitable que las características, peculiaridades y naturaleza del fenómeno bélico incidan en sus normas y de alguna manera modelen su contenido a fin de adaptarse a una actividad tan antigua como la propia humanidad. Sin embargo, la razón de ser del ius in bello es tratar de controlar los efectos devastadores de las hostilidades, imponiendo reglas de humanidad que protejan a las víctimas. Por eso, aunque ciertamente debe adecuarse a las características de los conflictos armados para seguir respondiendo a su propósito fundamental, en palabras de la Declaración de San Petersburgo de 1868, de "mitigar lo que sea posible las calamidades de la guerra", ello no significa que "deba forzosamente ceder a las presiones del momento y al desarrollo de los medios de destrucción". ${ }^{1}$

De ahí que, dentro del derecho internacional humanitario, el necesario acomodo a las características de los conflictos armados coexista con la exigencia de imponer límites a la violencia bélica, estableciendo estándares mínimos en la conducción de las hostilidades para proteger la dignidad humana en estas graves circunstancias. ${ }^{2}$ Mantener este delicado equilibrio sigue siendo el gran reto al que se enfrenta este sector normativo, especialmente en la actualidad, pues las transformaciones experimentadas en los conflictos armados a partir, sobre todo, de la posguerra fría, están teniendo un efecto devastador sobre las personas civiles, que siguen constituyendo la gran mayoría de las víctimas derivadas del desarrollo de las hostilidades. ${ }^{3}$

Entre este conjunto de cambios, la fragmentación y diversificación de los actores no estatales representan uno de los mayores desafíos para el

\footnotetext{
1 Pictet, Jean, Desarrollo y principios del derecho internacional bumanitario, Instituto Henry Dunant, Ginebra, 1986, p. 39.

2 Ver Schwarzenberger, Georg, "Functions and foundations of the laws of war", Archiv für Rets-und Sozialphilosopbie, 1958, 44, (3), p. 352.

3 Ver Moodie, Michael, "Conflicts trends in the $21^{\text {st }}$ century", Joint Force Quarterly, 2009,
} (53), p. 26. 
respeto del derecho internacional humanitario. ${ }^{4}$ Aunque históricamente no era inusual la presencia de grupos armados al margen de los ejércitos regulares, lo insólito en la actualidad es el espectacular incremento cuantitativo y cualitativo que han experimentado estos actores y su capacidad para poner en tela de juicio el monopolio estatal del uso legítimo de la violencia, hasta el punto de que han alterado sustancialmente el escenario bélico, en un contexto caracterizado por la proliferación de enfrentamientos en el interior de los Estados. ${ }^{5}$

Dentro de la amplia categoría de actores no estatales, llama especialmente la atención la presencia de contratistas privados -también denominados compañías militares y de seguridad privadas- que prestan servicios vinculados a la actividad militar y a la seguridad, en zonas de conflicto. No es un fenómeno nuevo, ${ }^{6}$ pero en los últimos tiempos ha adquirido una renovada pujanza por creciente tendencia a la externalización de ciertos servicios militares y de seguridad, que se ha reflejado en el número de empresas y en el personal desplegado en diferentes teatros de operaciones, ${ }^{7}$ así como en la

4 En efecto, como ha constatado el Secretario General de las Naciones Unidas, "[u]n factor determinante en el incumplimiento del derecho internacional por las partes armadas en los conflictos es que siguen predominando los conflictos armados no internacionales, que suelen caracterizarse por la proliferación y la fragmentación de los grupos armados no estatales". Informe del Secretario General sobre la protección de los civiles en los conflictos armados, Doc. S/2010/579, 11 de noviembre de 2010, párr. 7, p. 2.

5 En este sentido, ver García Rico, Elena del Mar, "Los conflictos armados del siglo xxi: ¿nuevos conflictos, viejas normas?”, en Martín y Pérez de Nanclares, J. (coord.), Estados y organizaciones internacionales ante las nuevas crisis globales, Iustel, Madrid, 2010, pp. 513-514; Laborie Iglesias, Mario, La privatización de la seguridad. Las empresas militares y de seguridad privadas en el entorno estratégico actual, Ministerio de Defensa, Madrid, 2013, p. 28.

6 Sobre el papel histórico de las empresas privadas en la organización de la actividad militar, ver Cockayne, James, "La reorganización mundial de la violencia legítima: las empresas militares y la cara privada del derecho internacional humanitario", International Review of the Red Cross, 2006, 88, (863), p. 274.

La importancia de estas empresas se pone de relieve en el caso de los Estados Unidos, que ha recurrido ampliamente a los contratistas privados, sobre todo en sus intervenciones en el extranjero, como Irak o Afganistán -escenarios en los que estos empleados han representado, al menos, la mitad de los efectivos desplegados-, aunque la progresiva reducción de tropas en ambos escenarios ha supuesto una disminución del personal de estas empresas. Ver Utilización de mercenarios como medio de violar los derechos humanos y obstaculizar el ejercicio del derecho de los pueblos a la libre determinación. Nota del Secretario General, Doc. A/68/339, 20 de agosto de 2013, párr. 33, p. 9; Schwartz, Moshe \& Church, Jennifer, Department of Defense's use of contractors to support military operations: background, analysis, and issues for Congress, Congressional Research Service, May 17, 2013, enhttp://www.fas.org/sgp/crs/natsec/R43074.pdf, consulta de noviembre 27 de 2013. 
importancia y diversidad de las funciones que desempeñan, lo que ha llevado a hablar de una 'privatización' de la violencia en los conflictos armados, pues su presencia se ha hecho indispensable en cualquier despliegue militar, aun entre los ejércitos más poderosos, como demuestran las intervenciones en Afganistán e Irak.

A tenor del papel relevante que desempeñan los contratistas privados en los conflictos armados y, sobre todo, de las críticas que han recibido por los comportamientos de sus empleados, es necesario clarificar el marco legal al que están sometidas estas empresas, para delimitar con mayor precisión el alcance de sus derechos y obligaciones en relación con el respeto de los derechos humanos, y establecer, en su caso, sus posibles responsabilidades y las de los Estados que recurren a sus servicios.

En este sentido, al margen de que estas empresas deban ser objeto de una regulación específica, su presencia en los conflictos armados representa un reto para la aplicación del derecho internacional humanitario, pues, ante la falta de referencias explícitas a este nuevo actor, se corre el riesgo de considerar que las actividades de los contratistas privados "potentially fall into a troublesome gray area with respect to human rights protections in armed conflict". Esta aparente indefinición no significa que exista un vacío legal o 'limbo jurídico' en relación con este sector normativo, sino que, como pondremos de relieve a lo largo de este trabajo, la obligación de respetar el derecho internacional humanitario se extiende también a los empleados de estas empresas, como actores participantes en un conflicto armado, del mismo modo que al personal militar.

\section{Impacto del creciente protagonismo de los contratistas privados en los conflictos armados en la aplicación del derecho internacional humanitario}

La participación de las compañías militares y de seguridad privadas en los conflictos armados ha resultado controvertida, especialmente por la implicación de sus empleados en algunos escándalos relacionados con violaciones

\footnotetext{
8 Kincade III, Mathew, "The private military company complex in Central and Southern Africa: the problematic application of international humanitarian law", Washington University Global Studies Law Review, 2013, 12, (1), p. 206. En la misma línea, ver Rosemann, Nils, "The privatization of human rights violations - Business' impunity or corporate responsibility? The case of human rights abuses and torture in Iraq", Non-State Actors and International Law, 2005, 5, (1), p. 89.
} 
de los derechos humanos y del derecho internacional humanitario, como las torturas cometidas contra los detenidos en la cárcel iraquí de Abu Ghraib o la muerte de civiles como consecuencia del uso excesivo e indiscriminado de la fuerza por empleados de Blackwater en la plaza de Nisour en Bagdad. ${ }^{9}$ Asimismo, estas empresas han sufrido numerosos ataques y bajas entre sus empleados en escenarios como Irak o Afganistán.

Por ello, es importante determinar si el derecho internacional humanitario puede servir como marco regulador de este tipo de actores. Esta labor de clarificación del alcance de los derechos y obligaciones de estas empresas y de sus empleados es especialmente importante, pues permite rechazar la supuesta existencia de un vacío legal del que se aprovechan a menudo dichas compañías, y los Estados que las contratan, ${ }^{10}$ para eludir el respeto de tales normas y asegurarse una impunidad de facto que les permitiría actuar al margen de la ley, ante las carencias e inadecuaciones del actual marco legal. ${ }^{11}$ En consecuencia, la ausencia de una reglamentación internacional específica de sus actividades no permite a estas compañías actuar al margen de las reglas jurídicas que imponen límites a los servicios que pueden prestar, al comportamiento de sus empleados sobre el terreno y que establecen las correspondientes responsabilidades en caso de incumplimiento de estas. ${ }^{12}$

9 En el caso de esta compañía no se trata de un caso aislado, pues sus empleados se han visto implicados en casi 200 incidentes de este tipo en Irak desde 2005 (en el $80 \%$ de los cuales fueron ellos quienes efectuaron los primeros disparos). Ver Informe del Grupo de Trabajo sobre la Utilización de Mercenarios como medio de violar los derechos humanos y obstaculizar el ejercicio del derecho de los pueblos a la libre determinación, Doc. A/HRC/15/25, 5 de julio de 2010, párrs. 19-20, p. 7.

10 Resulta pertinente recordar que, como afirmó el Comité de Derechos Humanos, "el hecho de otorgar contratos al sector comercial privado para que se encarguen de actividades estatales básicas que incluyen el uso de la fuerza y la detención de personas no exime a un Estado parte de sus obligaciones con arreglo al pacto", Comunicación 1020/2002, Cabaly Pasini c. Australia (dictamen aprobado el 7 de agosto de 2003, $78^{\circ}$ período de sesiones), en Informe del Comité de Derechos Humanos, Volumen II, Asamblea General. Documentos Oficiales. $58^{\circ}$ período de sesiones. Suplemento $N^{\circ} 40$ (A/58/40), Naciones Unidas, Ginebra, 2003, párr. 7.2, p. 367.

11 Sobre las trabas procesales que dificultan la persecución de los contratistas privados, ver Quirico, Ottavio, “The criminal responsibility for private military and security company personnel under international humanitarian law”, in Francioni, F. \& Ronzitti, N. (eds.), War by contract. Human rights, humanitarian law and private contractors, Oxford University Press, Oxford, 2011, pp. 442-445.

12 Ver Doswald-Beck, Louise, "Private military companies under international humanitarian law", in Chesterman, S. \& Lehnardt, Ch. (eds.), From mercenaries to market: the rise and regulation of private military companies, Oxford University Press, Oxford, 2007, p. 115. 
El derecho internacional humanitario no regula específicamente la situación de las compañías militares y de seguridad privadas, ni el estatuto de su personal, salvo en el improbable caso en que puedan ser considerados mercenarios. ${ }^{13}$ Esto no significa que no sea aplicable a este tipo de empresas, ni que sea imposible determinar el alcance de los derechos y las obligaciones de sus empleados cuando operen en un conflicto armado internacional o interno recurriendo a las normas y principios actualmente en vigor, pues dispone de los mecanismos e instrumentos interpretativos necesarios para ello. Aunque no haya sido elaborado pensando en estos nuevos actores, ${ }^{14}$ está claro que el derecho internacional humanitario constituye el marco jurídico al cual deben someterse todas las partes en conflicto, con independencia de su naturaleza, y del que se benefician todas las víctimas. Es más, este sector normativo ha mostrado la suficiente flexibilidad para adaptarse a los incesantes cambios experimentados por los conflictos armados. El objetivo de proteger a quienes no participan en los enfrentamientos y limitar sus sufrimientos en cualquier circunstancia, como expresión de las 'consideraciones elementales de humanidad', ha permitido ir avanzando hacia una interpretación progresiva, en clave teleológica, del ius in bello que ha facilitado la acomodación de sus normas a las nuevas realidades. ${ }^{15}$

Por lo tanto, se debe descartar cualquier tipo de interpretación que aluda a una supuesta falta de adecuación del derecho internacional humanitario para reglamentar las actividades de las compañías militares y de seguridad privadas y de su personal en los conflictos armados. Todo lo contrario, la capacidad de adaptación que ha demostrado este sector normativo demuestra que constituye el marco legal apropiado para regular los comportamientos de estas empresas. No solo impone obligaciones a sus directivos y sus empleados cuando presten sus servicios en un entorno bélico, especialmente si suponen una participación directa en las hostilidades, sino que también

13 En esta línea, ver Thürer, Daniel\& Maclaren, Malcolm, "Military outsourcing as a case study in the accountability and responsibility of power", in Reinisch, A.\& Kriebaum, U. (eds.), The law of international relations. Liber Amicorum Hanspeter Neubold, Eleven Publishing International, Utrech, 2007, p. 359.

14 En este sentido, ver Walker, Clive\& Whyte, Dave, "Contracting out war? Private military companies, law and regulation in the United Kingdom", International and Comparative Law Quarterly, 2005, 54, (3), p. 687.

$15 \mathrm{Al}$ respecto, ver Reydams, Luc, “À la guerre comme à la guerre: patterns of armed conflict, humanitarian law responses and new challenges", International Review of the Red Cross, 2006, 88, (864), p. 755. 
impide que queden sometidos a la arbitrariedad del adversario cuando se encuentren fuera de combate o caigan en su poder, pues en tal caso se les garantiza un régimen de protección. ${ }^{16}$ Asimismo, el derecho internacional humanitario impone obligaciones a los Estados en relación con las actividades de estas empresas, tal como se deriva del artículo $1^{\circ}$ común a los convenios de Ginebra de 1949, dado que el deber de respetar y hacer respetar el ius in bello 'en toda circunstancia' obliga a los Estados a garantizar que sus órganos y todas las personas que se encuentren bajo su jurisdicción respeten estas normas, y les prohíbe invocar cualquier razón, ya sea de carácter legal o de otra naturaleza, para no cumplir con tales reglas. ${ }^{17}$

La expresión más clara de la capacidad de adaptación de este sector normativo a nuevas realidades no expresamente previstas, fruto de los incesantes cambios en la naturaleza y características de los conflictos armados, así como en la tecnología militar, la encontramos en el reconocimiento de la llamada cláusula Martens. Al proclamar que en los casos no contemplados en los textos convencionales, las personas civiles y los combatientes quedan bajo la protección y el imperio de los principios del derecho de gentes derivados de los usos establecidos, de los principios de humanidad y de los dictados de la conciencia pública, esta disposición se configura como una especie de cláusula de cierre que asegura a toda persona una protección humanitaria básica en cualquier circunstancia no regulada expresamente. ${ }^{18}$ Se reconoce así la existencia de una serie de normas y principios fundamentales "que informan el conjunto del derecho internacional humanitario, que ejercen una función de parámetro interpretativo, que mantienen su validez fuera del contexto convencional y que conservan su obligatoriedad para aquellas situaciones no reguladas por los distintos convenios". ${ }^{19}$

16 En este sentido, se ha pronunciado el Comité Internacional de la Cruz Roja con carácter general en relación con las empresas que llevan a cabo sus actividades en países en los que existen conflictos armados. Ver Empresas y derecho internacional humanitario: introducción a los derechos y las obligaciones de las empresas comerciales, de conformidad con el derecho internacional humanitario, CICR, Ginebra, 2007, p. 7.

17 Boisson de Chazournes, Laurence\& Condorelli, Luigi, "Common article $1^{\circ}$ of the Geneva Conventions revisited: protecting collective interests", International Review of the Red Cross, 2000, 82, (837), p. 69.

18 En este sentido, se pronunció el Tribunal Militar de los Estados Unidos tras la Segunda Guerra Mundial en el caso Krupp. Vid. Trials of War Criminals before the Nurenberg Military Tribunals under Control Council Law N ${ }^{\circ}$ 10. Nurenberg. October 1946-April 1949, vol. IX, Government Printing Office, Washington, 1950, p. 1341.

19 Pons Rafols, Xavier, "Revisitando a Martens: las normas básicas de humanidad en la 
Así, los principios contenidos en la cláusula Martens refuerzan la aplicación de este corpus normativo, pues la ausencia de reglas expresas que regulen una situación concreta no significa que se autorice todo comportamiento que atente contra tales principios. ${ }^{20}$ Esta circunstancia permite aplicar el derecho internacional humanitario a los nuevos actores que operan en el marco de los conflictos armados actuales, como los contratistas privados, en la medida en que esta cláusula impide que ninguna parte en conflicto quede fuera del ámbito de las obligaciones dimanantes del ius in bello, ni que ninguna víctima quede desprotegida. ${ }^{21}$ Por eso, no es admisible la existencia de fenómenos o realidades que queden fuera de la aplicación de estas normas con la excusa de su pretendido carácter novedoso o de la ausencia de una regulación específica, ya que la aplicación de la mencionada cláusula significa que, "aunque los Estados no logren un acuerdo acerca de un asunto en particular, la conducción de la guerra siempre estará regida por los principios existentes del derecho internacional", ${ }^{22}$

Al margen de la necesidad de dotar a las compañías militares y de seguridad privadas de una regulación específica que delimite sus tareas y precise sus obligaciones, así como las de los Estados que intervienen en su contratación, se debe reiterar que el personal de estas empresas se halla, en todo caso, sometido al derecho internacional humanitario, ${ }^{23}$ cuyas normas se aplican a todos los actores implicados en un conflicto armado, participen

Comisión de Derechos Humanos", en Salinas de Frías, A. \& Vargas Gómez-Urrutia, M. (coords.), Soberanía del Estado y derecho internacional. Homenaje al profesor Juan Antonio Carrillo Salcedo, tomo II, Universidad de Córdoba/Universidad de Sevilla/Universidad de Málaga, Sevilla, 2005, p.1101.

20 En este sentido, ver Pérez González, Manuel, "Principios y 'leyes' de humanidad en situaciones de conflicto. Valor de la cláusula Martens a la luz del derecho internacional humanitario", en Rodríguez-Villasante y Prieto, J. L. \& López Sánchez, J. (coords.), La protección de la dignidad de la persona y el principio de bumanidad en el siglo XXI. Estudios de derecho internacional bumanitario, derechos bumanos y función policial in memoriam Gonzalo Jar Couselo, Tirant lo Blanch, Valencia, 2012, p. 119.

21 En esta línea, se ha pronunciado el Tribunal Penal Internacional para la antigua Yugoslavia (TPIY) en el caso Kuprestic. Vid. The Prosecutor v. Kupreskic et al., Case IT-95-16-T, Judgement of 14 January 2000, par. 525.

22 Kalshoven, Frits\& Zegveld, Liesbeth, Restricciones en la conducción de la guerra. Introducción al derecho internacional humanitario, CICR, Ginebra, 2001, p. 25.

23 Ver Gillard, Emanuela-Chiara, «Quand l'entreprise s'en va-t-en guerre: les sociétés militaires et sociétés de sécurité privées et le droit international humanitaire », International Review of the Red Cross, 2006, 88, (863), p. 176. 
directamente en las hostilidades o no, y protegen los derechos de las víctimas. Así se deriva del Documento de Montreux, que constituye el primer intento de clarificación de las obligaciones jurídicas a las que se hallan sometidos los Estados, las compañías militares y de seguridad privadas y sus empleados, y en el que se proponen un conjunto de buenas prácticas destinado a promover el respeto de las normas humanitarias. ${ }^{24}$

En este texto, elaborado a iniciativa del Comité Internacional de la Cruz Roja y del gobierno suizo, se recoge con claridad el deber de los empleados de estas compañías de respetar el derecho internacional humanitario, independientemente de su estatuto. ${ }^{25}$ Se debe destacar que esta afirmación figura en la parte primera del documento en la que se recogen las obligaciones jurídicas internacionales a las que están sometidos los Estados y las propias empresas militares y de seguridad privadas, lo que viene a reforzar su carácter vinculante. Así, los contratistas privados que presten sus servicios en una zona de conflicto deben cumplir tales normas y, en caso de violación, quedarán sometidos a las responsabilidades que a tal efecto se prevén, tanto en el plano interno como en el internacional.

\section{E1 respeto del derecho internacional humanitario como una obligación de los contratistas privados en la prestación de sus servicios en el contexto bélico}

Aunque no existan referencias expresas en el derecho internacional humanitario a las compañías militares y de seguridad privadas, se debe destacar, como ya se ha avanzado, que la aplicación de sus normas a estas empresas y sus empleados deriva de la naturaleza misma de las obligaciones que impone este sector normativo a todas las partes en conflicto, pues están concebidas para producir efectos jurídicos no solo sobre los Estados, sino también sobre los individuos. ${ }^{26}$ En efecto, el respeto de las normas humanitarias no se

24 Sobre el impacto del Documento de Montreux en la aplicación del derecho internacional humanitario, ver Seger, Paul, "The Swiss initiative on private military and security companies", in Odello, M. \& Beruto, G. L. (eds.), Non-State actors and international humanitarian law. Organized armed groups: a challenge for the 21 $1^{\text {st }}$ century, FrancoAngeli, Milano, 2010, pp. 121-123.

25 Documento de Montreux sobre las obligaciones juridicas internacionales pertinentes y las buenas prácticas de los Estados en lo que respecta a las operaciones de las empresas militares y de seguridad privadas durante los conflictos armados. Montreux, 17 de septiembre de 2008, Doc. A/63/467-S/2008/636, 6 de octubre de 2008, p. 12.

26 Ver Kalshoven\& Zegveld, Restricciones..., op. cit., p. 87; David, Eric, Principes de droit des conflits armés, 4éd., Bruylant, Bruxelles, 2008, p. 248. 
circunscribe a los agentes estatales, sino que se extiende a cualquier persona, grupo armado o entidad privada que intervenga o participe en un conflicto armado, internacional o interno. ${ }^{27}$

Los contratistas privados no son los primeros actores no estatales que han planteado dificultades a la aplicación del derecho internacional humanitario, sino que este problema ya se ha suscitado en relación con los grupos rebeldes que luchan contra las autoridades gubernamentales en un conflicto armado interno, admitiéndose en la actualidad que en tales situaciones los insurgentes están sometidos a ciertas obligaciones independientemente de que hayan sido reconocidos por el Estado contra el que luchan o por un tercer Estado. ${ }^{28}$ Esta es una conclusión que se deriva del propio artículo $3^{\circ}$ común a los convenios de Ginebra de 1949. A tenor de su redacción, las obligaciones contenidas en él se imponen a "cada una de las partes contendientes", sin que se precise la naturaleza de los actores intervinientes, lo que nos permite aplicar esta disposición a los grupos armados que tomen parte en un conflicto, pero también a cualquier otra entidad que participe directamente en las hostilidades. ${ }^{29}$ Esta redacción tan amplia permitiría in-

27 En este sentido, se pronunció el Tribunal Militar de los Estados Unidos al juzgar a diferentes industriales alemanes por su participación en los crímenes cometidos en la Segunda Guerra Mundial, como en el caso Krupp, en el que afirmó: "The laws and customs of war are binding no less upon private individuals than upon government officials and military personnel" (Trials of War Criminals..., op. cit., p. 1375); en esta línea, se expresó también en el caso Flick (ibíd., vol. VI, pp. 1191-1192) o en el caso Zyklon B (Law Reports of Trials of War Criminals, vol. I, United Nations War Crimes Commission, London, 1947, p. 103). Desde entonces, otros tribunales penales internacionales han confirmado esta interpretación del alcance de las normas humanitarias. Así lo hizo el Tribunal Penal Internacional para Ruanda (TPIR) (ver Appeals Chamber, The Prosecutor v. Jean-Paul Akayesu, Case ICTR-96-4-A, Judgement of $1^{\circ}$ June 2001, par. 443) o el Tribunal Especial para Sierra Leona. Ver Prosecutor v. Sam Hinga Norman, Case SCSL-2004-14-AR72(E),Decision on Preliminary Motion Based on Lack of Jurisdiction (Child Recruitment), 31 May 2004, par. 22. En la doctrina, ver David, Eric, " "Le droit international humanitaire et les acteurs non étatiques », in College of Europe, Lapertinence du droit international humanitaire pour les acteurs non-étatiques. Actes du Colloque de Bruges, 25-26 octobre 2002, College of Europe, Bruges, 2003, pp. 28-29.

28 Ver Clapham, Andrew, "Human rights obligations of non-state actors in conflict situations", International Review of the Red Cross, 2006, 88, (863), p. 493.

29 Así se ha pronunciado la Comisión Interamericana de Derechos Humanos en el asunto del cuartel de La Tablada: "Las disposiciones obligatorias del artículo $3^{\circ}$ común obligan y se aplican expresamente por igual a ambas partes de los conflictos internos, vale decir el gobierno y las fuerzas disidentes". Informe 55/97, Caso 11.137 Juan Carlos Abella (Argentina), 18 de noviembre de 1997, párr. 174. En la misma línea, se sitúa la Comisión de la Verdad y Reconciliación de Perú (Comisión de la Verdad y Reconciliación. Informe final, tomo I, Lima, 2003, p. 203) o el 
cluir dentro de su ámbito de aplicación a otros actores no estatales, como las compañías militares y de seguridad privadas, sobre todo aquellas con capacidad para movilizar recursos militares y que prestan servicios armados. Ello sería plenamente consecuente con el objeto y fin de esta disposición que en palabras del TPIR es "to broaden the application of the international bumanitarian law by defining what constitutes minimum humane treatment and the rules applicable under all circumstances" 30

Esta posición se ha visto respaldada por la Resolución del Instituto de Derecho Internacional, aprobada el 25 de agosto de 1999 en su sesión de Berlín, sobre la aplicación del derecho internacional humanitario y los derechos humanos fundamentales en los conflictos armados en los que toman parte entidades no estatales. En ella se establece con claridad que las entidades no estatales son destinatarias de las normas del ius in bello del mismo modo que los Estados. ${ }^{31}$ Se adopta así en este texto un enfoque no formalista, sino más bien de carácter funcional, del derecho internacional humanitario que es plenamente consecuente con la práctica internacional; ${ }^{32}$ con él se busca extender lo más posible el ámbito de

TPIR en la sentencia del $1^{\circ}$ de junio de 2001 de su Sala de Apelación en el caso Akayesu: "It must be noted that article $3^{\circ}$ common to the Geneva Conventions does not identify clearly the persons covered by its provisions nor does it contain any explicit reference to the perpetrator's criminal liability for violation of its provisions. The chapeau of common article $3^{\circ}$ only provides that 'each party to the conflict shall be bound to apply, as a minimum, the following provisions'. The primary object of this provision is to bighlight the 'unconditional' character of the duty imposed on each party to afford minimum protection to persons covered under common article $3^{\circ " .}$. The Prosecutor v. Jean-Paul Akayesu..., op. cit., par. 437. En la doctrina, ver Zegveld, Liesbeth, The accountability of armed opposition groups in international law, Cambridge University Press, Cambridge, 2002, pp. 10-12; Fleck, Dieter, "International humanitarian law after September 11: challenges and the need to respond", Yearbook of International Humanitarian Law, 2003, 6, pp. 52-53.

30 The Prosecutor v. Jean-Paul Akayesu..., op. cit., par. 442. En este mismo sentido, se pronunció el тPIY en el caso Celebici. Vid. Appeals Chamber, The Prosecutorv. Zejnil Delalic, Zdravko Mucic (aka Pavo'), Hazim Delic and Esad Lanď̌o (aka 'Zenga') ('Celebici Case'), Case IT-96-21-A, Judgement of 20 February 2001, par. 143.

31 En efecto, en el parrafo II de la Resolución se dispone que "[t]outes les parties aux conflits armés auxquels prennent part des entités non étatiques, indépendamment de leur statut juridique, de même que les Nations Unies et les organisations régionales et autres organisations internationales compétentes, ont l'obligation de respecter le droit international bumanitaire de même que les droits fondamentaux de l'homme".

32 Esta perspectiva se adopta en los comentarios de los convenios de Ginebra de 1949 a la hora de definir el ámbito de aplicación del artículo $3^{\circ}$ común, pues se señala que el término "parte en conflicto" "on n'exige même pas qu'elle représente une entité juridique capable de s'engager internationalement". Es más, reitera a continuación en esta misma línea que "[c] hacune des parties sera donc tenue d'appliquer l'article $3^{\circ}$, par le seul fait qu'elle existe et qu'un conflit armé l'oppose à l'autre. L'obligation est, pour chacune d'elles, inconditionnelle et unilatérale". Pictet, Jean S. (dir.), Commentaire 
aplicación de sus normas para asegurar que cualquier persona o entidad que participe efectivamente en un conflicto, al margen de su naturaleza jurídica, quede sometida a obligaciones concretas en relación con la conducción de las hostilidades y el trato debido a las personas que no tomen parte en los enfrentamientos o que hayan quedado fuera de combate.

Los criterios que se deben tener en cuenta con carácter preferente son el grado de organización de los actores no estatales y su capacidad para tomar parte activamente en operaciones militares. ${ }^{33}$ Desde ese preciso momento, cualquier grupo armado se halla obligado a respetar las normas del derecho internacional humanitario que resulten aplicables con independencia del propósito que les anime en su participación en actos de violencia o de los objetivos que pretendan alcanzar. ${ }^{34}$ Esta perspectiva favorece la protección de las víctimas frente a interpretaciones de carácter legalista que supongan la exoneración de alguna entidad que participe en el conflicto del respeto de obligaciones que son consideradas esenciales para la salvaguardia del ser humano.

Esta resolución está pensada sobre todo para los grupos guerrilleros que participan en un conflicto armado interno, pero no existe ninguna razón para no extender lo dicho respecto de ellos en relación con la aplicación del derecho internacional humanitario a las compañías militares y de seguridad privadas cuando en la prestación de sus servicios se vean implicadas en actos hostiles. La perspectiva funcional que se ha adoptado para definir a los grupos armados que toman parte en un conflicto interno -basada en el grado de organización y en su capacidad para emprender operaciones militares- también se podría aplicar mutatis mutandis a los contratistas privados en la medida en que lleven a cabo tareas que impliquen una participación directa en las hostilidades, ${ }^{35}$ como la realización de servicios de seguridad de

de la Convention de Genève pour l'amélioration du sort des blessés et des malades dans les forces armées en campagne, Comité International de la Croix-Rouge, Genève, 1952, p. 54.

33 Al respecto, ver Ben Mahfoudh, Haykel, « Acteurs non étatiques et conflits armés non internationaux », in Ben Achour, R.\& Laghmani, S. (dirs.), Acteurs non étatiques et droit international, Pedone, Paris, 2007, p. 229.

34 En esta línea, se ha pronunciado el TPIY. Ver Trial Chamber II, The Prosecutor v. Fatmir Limaj, Haradin Bala, Isak. Musliu, Case IT-03-66-T, Judgement of 30 November 2005, par. 170.

35 Sin entrar en el arduo debate que rodea a la interpretación de esta expresión, se puede señalar que la participación directa en las hostilidades aludiría a todos aquellos actos de guerra que por su naturaleza o propósito están dirigidos a causar daños al personal o a los recursos materiales del ejército enemigo. La participación directa, que incluye tanto las acciones 
personalidades, edificios, infraestructuras o convoyes, el manejo de sistemas de armamento -como los vehículos aéreos no tripulados-, determinadas actividades de inteligencia o la participación en operaciones de contrainsurgencia. $^{36}$

A tenor de ello, habría que tener en cuenta la naturaleza de las tareas que llevan a cabo y su capacidad para desplegar unidades armadas en el teatro de operaciones. Algunas de estas empresas, como en su momento Executive Outcomes, Sandline International o Academi -anteriormente Blackwater y después Xe Services-, han demostrado que están en condiciones de pro-

ofensivas como las defensivas, implica la existencia de una relación de causalidad directa entre la actividad realizada por la persona y el daño ocasionado al enemigo en el momento y en el lugar en el que se lleva a cabo. Esta noción no se limita a la intervención en actos hostiles contra el enemigo, sino que incluye otras tareas, como el transporte de armas en el teatro de las operaciones, la transmisión de información militar para su uso inmediato en los ataques o servir como guardias, agentes de inteligencia u observadores al servicio de las fuerzas armadas. Otro tipo de actividades no tienen que significar una participación directa. Así lo ha confirmado la jurisprudencia del TPIY, entre otros, en los casos Celebici (The Trial Chamber II, The Prosecutor v. Zejnil Delalic, Zdravko Mucic also known as 'Pavo', Hazim Delic, Esad Landzo also known as 'Zenga', Case NIT-96-21-T, Judgement of 16 November 1998, par. 568) o Strugar (Appeals Chamber, The Prosecutor v. Pavle Strugar, Case NIT-01-42-A, Judgement of 17 July 2008, par. 173). En esta última sentencia, el TPIY hace, además, una enumeración de ejemplos de participación indirecta recogidos en la práctica: participar en actividades en apoyo al esfuerzo de guerra de una parte en el conflicto; la venta de bienes a uno de los contendientes; manifestar apoyo a la causa de una de las partes en el conflicto; no actuar para evitar la incursión de una de las partes en el conflicto; acompañar y suministrar alimentos a uno de los contendientes; recopilar y transmitir información militar, transportar armas y municiones, y proporcionar los suministros; o proporcionar asesoramiento especializado sobre la selección de personal militar, su formación o el mantenimiento correcto de las armas (ibíd., par. 177). Sobre los elementos constitutivos de la participación directa en las hostilidades, ver Melzer, Nils, Guía para interpretar la noción de participación directa en las hostilidades según el derecho internacional bumanitario, CICR, Ginebra, 2010, pp. 46-64. Aunque no existe una definición clara y uniforme de participación directa en las hostilidades (ver Henckaerts, Jean-Marie \& Doswald-Beck, Louise, El derecho internacional humanitario consuetudinario, vol. I, CICR, Buenos Aires, 2007, p. 26), esta interpretación restrictiva, pese a que no es unánimemente admitida, resulta más acorde con la aplicación del principio de distinción y con presunción del carácter civil de las personas en caso de duda, prevista en el artículo 50, 1 del Protocolo Adicional I de 1977. Al respecto, ver David, Principes de droit..., op. cit., pp. 286-287; Sossai, Mirko, "Status of private military and security company personnel in the law of international armed conflict", in Francioni \& Ronzitti, War by contract..., op. cit., pp. 204-206.

36 Al respecto, ver McDonald, Avril, "Ghosts in the machine: some legal issues concerning us military contractors in Iraq", in Schmitt, M. N. \& Pejic, J. (eds.), International law and armed conflict: exploring the faultlines. Essays in honour of Yoram Dinstein, Martinus Nijhoff Publishers, Leiden, 2007, pp. 384-385. 
porcionar a los Estados o a otras entidades contratantes servicios militares que supongan una implicación directa en un conflicto. En estos casos, las empresas y su personal están obligados a respetar las normas y principios fundamentales del derecho internacional humanitario durante el desarrollo de las tareas que les hayan sido encomendadas, de igual modo que lo está el personal militar, en relación con los potenciales adversarios y las posibles víctimas de sus acciones, sin que quepa ningún tipo de exoneración. ${ }^{37}$

A tal efecto, adquiere una especial importancia el artículo $3^{\circ}$ común, pues en él se contiene el conjunto de reglas esenciales que todo contendiente debe cumplir en cualquier situación de violencia bélica, y que por ello constituyen la expresión normativa más clara de las consideraciones elementales de humanidad. ${ }^{38}$ Entre ellas, se debe destacar la obligación de tratar humanamente a todas las víctimas de los conflictos armados y, en particular, a las personas que se encuentren en su poder. Como una manifestación de dicho principio, se prohíbe cualquier atentado contra su vida y su integridad corporal, y, sobre todo, las ejecuciones extrajudiciales, arbitrarias y sumarias; ${ }^{39}$ el

37 Se debe advertir que el derecho internacional humanitario limita las tareas que pueden ser asignadas a contratistas privados, al atribuir el ejercicio de determinadas funciones específicamente a las autoridades estatales, como es el caso de la condición de oficial responsable de los campamentos de prisioneros de guerra (III Convenio de Ginebra de 1949, art. 39) o de los centros de internamiento de civiles (IV Convenio de Ginebra de 1949, art. 99). Así lo recuerda el Documento de Montreux al advertir a los Estados contratantes que están obligados a no contratar empresas privadas para llevar a cabo este tipo de actividades. Ver A/63/467S/2008/636, párr. 2, p. 7.

38 Así lo reconoció el TPIY en el caso Celebici cuando afirmó que "[t] hese principles were codified in common article $3^{\circ}$ to constitute the minimum core applicable to internal conflicts, but are so fundamental that they are regarded as governing both internal and international conflicts", concluyendo que "[t]hese rules may thus be considered as the 'quintessence' of the humanitarian rules" (Appeals Chamber, The Prosecutor v. Zejnil Delalic..., op. cit., par. 143). En la doctrina española, ver el esclarecedor trabajo de Pérez González, Manuel, "El artículo $3^{\circ}$ común a los convenios de Ginebra de 1949 como expresión normativa del 'poder de la humanidad': algunas reflexiones”, en Badía Martí, A. M.; Pigrau Solé, A. \& Olesti Rayo, A. (coords.), Derecho internacional y comunitario ante los retos de nuestro tiempo. Homenaje a la profesora Victoria Abellán Honrubia, vol. I, Marcial Pons, Madrid, 2009, p. 505.

39 A este respecto, cuando lleven a cabo actividades de seguridad no relacionadas con la conducción de las hostilidades, podrían resultar útiles las reglas de derechos humanos relativas al uso de la fuerza letal y, en particular, los Principios básicos sobre el empleo de la fuerza y de armas de fuego por los funcionarios encargados de hacer cumplir la ley, adoptados por el $8^{\circ}$ Congreso de las Naciones Unidas sobre Prevención del Delito y Tratamiento del Delincuente, celebrado en La Habana del 27 de agosto al 7 de septiembre de 1990. Así se reconoce en el Código Inter- 
empleo de la tortura o de otros tratos crueles, inhumanos o degradantes; ${ }^{40}$ o la toma de rehenes. A ello se debe sumar la obligación de recoger y cuidar a los heridos, enfermos y náufragos. Además de las obligaciones contenidas en el citado precepto, deben cumplir las normas relativas a la conducción de las hostilidades o al empleo de medios y métodos de combate en el caso de que participen en operaciones militares de carácter ofensivo o defensivo. ${ }^{41}$

Pero los empleados de las compañías militares y de seguridad privadas no solo van a estar obligados por el derecho internacional humanitario cuando presten sus servicios en el contexto de un conflicto armado, sino que también deben tener en cuenta determinadas normas de derechos humanos, a tenor de la complementariedad de ambos sectores normativos. ${ }^{42}$ En efecto, aunque estos actores no estatales no sean destinatarios directos de obligaciones de derechos humanos, es preciso tener en cuenta que tales reglas pueden servir en determinadas circunstancias de parámetro interpretativo de normas del ius in bello, sobre todo, cuando estas no sean lo sufi-

nacional de Conducta para Proveedores de Servicios de Seguridad Privada (párr. 32), al que aludiremos más adelante.

40 En el ius in bello, no se exige que la tortura sea cometida por "un funcionario público u otra persona en el ejercicio de funciones públicas, a instigación suya, o con su consentimiento o aquiescencia". Así lo ha confirmado la jurisprudencia del TPIY. Ver Droege, Cordula, "El verdadero Leitmotiv: la prohibición de la tortura y otras formas de malos tratos en el derecho internacional humanitario", International Review of the Red Cross, 2007, (867), pp. 228-229.

41 En consecuencia, sería ilícita la orden dada a sus empleados por Executive Outcomes -que operaba bajo contrato con el gobierno-, durante el conflicto en Sierra Leona, de llevar a cabo ataques aéreos contra los rebeldes para "matarlos a todos", a pesar de que hubieran advertido a sus superiores que no podían distinguir entre civiles y rebeldes.Ver Dickinson, Laura, "Government for hire: privatizing foreign affairs and the problem of accountability under international law", William and Mary Law Review, 2005, 47, (1), p. 153. Dentro de estas normas, deben respetar los siguientes principios: el derecho de las partes en conflicto a escoger los medios y los métodos de combate no es ilimitado, con la consiguiente prohibición de causar daños superfluos a los combatientes; el deber distinguir entre combatientes y población civil, así como entre objetivos militares y bienes civiles, con la prohibición de atacar a la población y los bienes civiles y la obligación de limitar en tanto sea posible los efectos de las hostilidades sobre estas personas y bienes. El carácter fundamental de estos principios ha sido destacado por el Tribunal Internacional de Justicia, que en el asunto de la legalidad de la amenaza o el empleo de armas nucleares ha afirmado que constituyen "principios intransgredibles del derecho internacional consuetudinario". Ver el texto de la opinión consultiva del 8 de julio de 1996 en Doc. A/51/218, 19 de julio de 1996, párr. 79.

42 En este sentido, ver Ryngaert, Cedric, "Human rights obligations and armed groups", Revue Belge de Droit International, 2008, 41, (1-2), pp. 377-378. 
cientemente claras, como puede ocurrir en casos de ocupación militar o de conflicto armado interno. ${ }^{43}$

\section{Regulación de las actividades de las compañías militares y de seguridad privadas en los conflictos armados como medio para promover el respeto del derecho internacional humanitario}

Como acabamos de ver, la aplicación del derecho internacional humanitario a las compañías militares y de seguridad privadas deriva de la propia naturaleza de las obligaciones que impone a las partes en conflicto. Pero el cumplimiento de estas normas se verá reforzado y promovido por los diferentes intentos de regulación de las actividades de estas empresas, especialmente cuando presten sus servicios en un entorno bélico, para tratar de delimitar las tareas que pueden llevar a cabo, para definir las reglas de conducta a las que están sometidos sus empleados en la prestación de sus servicios y para clarificar las obligaciones de los Estados implicados.

Estas iniciativas, que se mueven entre la elaboración de un tratado internacional y la autorregulación, permiten constatar la existencia una tensión entre dos modelos de regulación que son cada vez más relevantes en el ámbito de la seguridad: "A state-backed approach that emphasizes a patchwork of hard law obligations; and an industry-backed approach that encourages cross-jurisdictional regulatory harmonization to reduce transaction costs and help secure industry investments". ${ }^{44}$ Fruto de esta tensión, que tiene una dimensión más general, se constata una pérdida de interés por recurrir a tratados multilaterales generales en beneficio de lo que se denominan las nuevas formas de normatividad, jurídicas y no jurídicas. ${ }^{45}$ De ahí que la regulación de las actividades de estas

\footnotetext{
$43 \mathrm{Al}$ respecto, ver Pérez González, Manuel, "Las relaciones entre el derecho internacional de los derechos humanos y el derecho internacional humanitario", Cursos Euromediterráneos Bancaja de Derecho Internacional, 1997, I, p. 389.

44 Cockayne, James, "Regulating private military and security companies: the content, negotiation, weaknesses and promise of the Montreux Document", Journal of Conflict \& Security Law, 2009, 13, (3), p. 404.

45 En efecto, con carácter general, asistimos en la práctica a la creciente tendencia a recurrir "a regulaciones blandas en concertación con los operadores privados" y a "manifestaciones de autorregulación por parte de los actores privados", lo que ha llevado a la proliferación de instrumentos concertados no convencionales, declaraciones de principios, recomendaciones, estándares o códigos de conducta. Ver Andrés Sáenz de Santa María, Paz, "Las dinámicas del
} 
empresas se haya convertido en una tarea compleja que requiere un enfoque más amplio basado tanto en instrumentos legales como informales, y que tenga en cuenta la participación de un conjunto más amplio de actores junto a los Estados, como las organizaciones internacionales y no gubernamentales (ONG), los clientes privados y las propias empresas. ${ }^{46}$

Teniendo en cuenta las dificultades que plantea en estos momentos la regulación de las actividades de los contratistas privados, es necesario hacer un repaso de los diferentes modelos o propuestas de regulación que se han ido planteando, sin entrar en un análisis detallado de todas estas iniciativas, sino únicamente para constatar en qué medida está presente en ellas la obligación de respetar el derecho internacional humanitario por parte de estas empresas y sus empleados, pues estas regulaciones pueden contribuir a disipar dudas sobre la aplicación de este sector normativo y, con ello, pueden contribuir a reforzar su eficacia, sobre todo desde el punto de vista de la exigencia de responsabilidad.

\subsection{Obligatoriedad del derecho internacional humanitario en el marco de las iniciativas de autorregulación de las compañías militares y de seguridad privadas}

Como reflejo de la mencionada tendencia, han proliferado diversos textos de carácter voluntario aprobados en el marco de la llamada 'responsabilidad social corporativa', que entrarían dentro de la categoría del soft law. A través de ellos, se trata de clarificar las obligaciones de las empresas -entre las que se encuentran las compañías militares y de seguridad privadas- en relación con la protección de los derechos humanos y a los cuales podrían adherirse estas. ${ }^{47}$ Entre estos documentos, se deben destacar las Lineas directrices de la OCDE para empresas multinacionales, adoptadas por primera vez en junio de

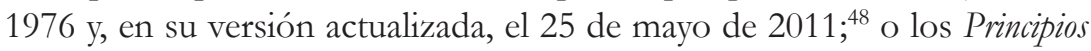

derecho internacional en el siglo xxi: acordes y desacordes", en Martín y Pérez de Nanclares, Estados y organizaciones..., op. cit., p. 88.

46 Ver Cusumano, Eugenio, "Policy prospects for regulating private military and security companies", in Francioni \& Ronzitti, War by contract..., op. cit., p. 11.

47 Ver Lapointe, Marie-Ève, «Le droit international humanitaire, à la merci des entreprises militaires et de sécurité privées? ", Revue Québécoise de Droit International, 2011, 24, (1), p. 96.

48 OCDE, Lineas directrices de la OCDE para empresas multinacionales. Revisión 2011, OECD Publishing, París, 2013, en http://dx.doi.org/10.1787/9789264202436-es, consulta de noviembre 8 de 2013. 
rectores sobre empresas y derechos humanos: puesta en práctica del marco de las Naciones Unidas para 'proteger, respetary remediar', aprobados en 2011 por el Consejo de Derechos Humanos. En estos textos, se insiste en que las empresas deben respetar los derechos humanos, que incluyen las normas del derecho internacional humanitario, en caso de conflicto armado. ${ }^{49}$ Otra iniciativa en esta línea, pero más orientada a las empresas de seguridad, se ha concretado en Losprincipios voluntarios sobre seguridady derechos humanos, elaborados en 2000 por algunos Estados, junto con las empresas extractivas de recursos minerales y energía, y algunas organizaciones no gubernamentales. En ellos se insiste de nuevo en el deber de las compañías de seguridad privada que presten sus servicios para dichas empresas de respetar las normas del derecho internacional humanitario.

Igualmente, la obligatoriedad de estas normas se ha destacado en las iniciativas de autorregulación llevadas a cabo dentro del sector de la seguridad, que se han concretado en la elaboración de códigos de conducta específicos por cada empresa o en la adhesión a alguno de los confeccionados por otras entidades, como asociaciones profesionales de estas compañías, en los que se establecen principios, pautas y reglas de comportamiento a los que deben someter sus actividades. ${ }^{50}$ Este tipo de textos, que suele servir como un elemento para reforzar la imagen de profesionalidad y respetabilidad de la compañía, ${ }^{51}$ plantea problemas relacionados con la concreción de las obligaciones asumidas por los contratistas y con la falta de mecanismos de supervisión que garanticen la exigencia de responsabilidad en caso de

49 En este sentido, ver Informe del representante especial del Secretario General para la cuestión de los derechos humanos y las empresas transnacionales y otras empresas, John Ruggie. Principios rectores sobre las empresas y los derechos humanos: puesta en práctica del marco de las Naciones Unidas para 'proteger, respetary remediar', Doc. A/HRC/17/31, 21 de marzo de 2011, p. 16.

50 Las principales asociaciones que agrupan a estas empresas -International Stability Operations Association (ISOA) o British Association of Private Security Companies (BAPSC) - han elaborado reglas o códigos de conducta en los que también se reconoce el deber que tienen sus empleados de actuar de conformidad con el derecho internacional humanitario. Así se recoge en el Código de Conducta de la ISOA, en http:/ / www.stability-operations.org/?page=Code, consulta de noviembre 10 de 2013; y en la Carta de la BAPSC, en http://www.bapsc.org. $\mathrm{uk} /$ ?keydocuments $=$ charter, consulta de noviembre 10 de 2013 . Sobre la autorregulación de las compañías militares y de seguridad privadas en relación con el respeto del derecho internacional humanitario, ver Bearpark, Andrew \& Schulz, Sabrina, "The future of the market", in Chesterman \& Lehnardt, From mercenaries to market..., op. cit., pp. 244-245.

51 En este sentido, ver De Nevers, Renée, "The effectiveness of self-regulation by the private military and security industry", Journal of Public Policy, 2010, 30, (2), pp. 222-223. 
infracciones cometidas por los empleados. ${ }^{52}$ Por eso, se ha afirmado oportunamente que estos códigos de conducta a menudo no constituyen más que "a public relations exercise, at best intended to improve the image of the corporation and a worst to whitewash corporate exploitation and delay the establishment of binding legal norms". 53

Con el propósito de superar estas críticas, a iniciativa de las principales asociaciones profesionales del sector, con el apoyo del gobierno suizo, se ha elaborado el Código internacional de conducta para proveedores de servicios de seguridad privada, suscrito el 9 de noviembre de 2010. En este nuevo código de conducta, se sistematizan una serie de principios y reglas que permiten a estas compañías operar de conformidad con el derecho internacional humanitario y el derecho internacional de los derechos humanos. A tal efecto, asumen el compromiso de respetar dichas normas, pero se debe destacar que no lo hacen de forma genérica, sino que se someten a obligaciones concretas que afectan el comportamiento de sus empleados. ${ }^{54}$ De este modo, el código lleva a cabo una labor de clarificación de los estándares a los que deben someterse estas empresas en el desempeño de las tareas encomendadas, que puede ser útil si son interiorizados por las compañías y se transforman en pautas de funcionamiento en el desarrollo de su actividad empresarial, sobre todo cuando lleve aparejada la prestación de servicios armados. ${ }^{55}$ Para

$52 \mathrm{Al}$ respecto, ver Reinisch, August, "The changing international legal framework for dealing with non-state actors", in Alston, P. (ed.), Non-State actors and human rights, Oxford University Press, Oxford, 2005, p. 52.

53 Engle, Eric, "Corporate Social Responsibility (CSR): market-based remedies for international human rights violations?”, Willamette Law Review, 2004, 40, (1), p. 113.

54 Según el párrafo 6, d) y e), del preámbulo, se comprometen "a adoptar medidas destinadas a establecer y a preservar un marco eficaz de gestión interna a fin de prevenir, controlar, informar y corregir de manera eficaz las repercusiones negativas que pueda haber en los derechos humanos" y "a crear los instrumentos necesarios para dar una respuesta a las denuncias interpuestas contra las actividades que infrinjan las leyes nacionales o internacionales vigentes o este código" (texto del Código Internacional de Conducta, en http://www.icoc-psp.org, consulta de noviembre 4 de 2013). Estos compromisos ponen el énfasis en la necesidad de establecer mecanismos de gobernanza y supervisión para garantizar que la gestión de las compañías sea respetuosa con los derechos humanos y para asegurar la aplicación efectiva de este código frente a comportamientos contrarios a los derechos humanos. En este sentido, ver Rosemann, Nils, Code of Conduct: tool for self-regulation for private military and security companies, Occasional Paper $N^{\circ} 15$, Geneva Centre for Democratic Control of Armed Forces, Geneva, 2008, pp. 5-6.

55 Para reforzar la aplicación de este código de conducta, se ha creado un mecanismo de vigilancia, denominado International Code of Conduct for Private Security Service Providers' 
conseguirlo, resulta oportuna la adopción de medidas, como las anunciadas por los Estados Unidos o el Reino Unido, ${ }^{56}$ que incentiven a estas empresas a respetar los principios y reglas establecidos en dicho código. A estas iniciativas se ha unido la propia Organización de las Naciones Unidas, que ha abogado por contratar únicamente a aquellas compañías que hayan suscrito este código de conducta. ${ }^{57}$

No se puede negar que este modelo de autorregulación resulta útil para promover el respeto del derecho internacional humanitario, pues en los textos mencionados se reconoce que tales normas son aplicables a las actividades de estas empresas. Pero, a pesar de los esfuerzos del sector-alentados por algunos Estados- de dotarse de una cierta regulación por esta vía, estas iniciativas no podrán desprenderse de una sensación de falta de legitimidad de los contratistas privados ante la opinión pública en general para decidir por sí mismos cuál es el alcance de sus obligaciones en relación con el derecho internacional humanitario, ${ }^{58}$ sobre todo cuando algunas de las empresas signatarias tienen antecedentes de graves violaciones de estas normas. Iniciativas como esta tendrían que encuadrarse en un marco legal más amplio

Association (ICoCA). Se trata de una institución independiente creada con el propósito de promover, regular y supervisar la aplicación del código y promover la prestación responsable de los servicios de seguridad y el respeto de los derechos humanos, así como del derecho interno e internacional, de conformidad con el código (art. $2^{\circ}, 2$ de articles of Association). Las compañías que quieran someterse a este mecanismo deberán formar parte de la ICoCA, a quien corresponde certificar que la empresa cumple con los principios y reglas del código y que está sometida a supervisión, auditoría y verificación, incluso sobre el terreno. A través de este mecanismo, se pueden tomar medidas contra las empresas que incumplan las reglas contenidas en el código. La ICoCA está operativa y ha comenzado sus actividades en septiembre de 2013.

56 En este sentido, el Departamento de Estado ha avanzado en que incorpora la pertenencia a la ICoCA como un requisito para la contratación de estas empresas (State Department to Incorporate International Code of Conduct into Worldwide Protective Services Contracts, Media Note. Office of the Spokesperson. Washington, D.C., August 16, 2013); y el Ministerio de Asuntos Exteriores británico ha anunciado la puesta en marcha de un sistema de certificación nacional de los estándares profesionales de estas empresas basado en los principios y reglas previstos en el código (International Code of Conduct for Private Security Providers Association. Written Statement to Parliament, 15 October 2013).

57 Así se refleja en el documento elaborado por el Departamento de Seguridad de las Naciones Unidas, Guidelines on the use of armed security services from private security companies, UN Security Management System: Security Management Operations Manual, 8 November 2012, \$25(a).

$58 \mathrm{Al}$ respecto, ver Cockayne, James \& Mears, Emily Speers, Private military and security companies: a framework for regulation, International Peace Institute, New York, 2009, p. 4. 
que concretase las obligaciones de los diferentes Estados implicados en la contratación de estas sociedades y sus eventuales responsabilidades. ${ }^{59}$ De ahí que por sí solos no constituyan una garantía suficiente del cumplimiento de las normas del ius in bello, pero sí un medio complementario valioso a otros instrumentos jurídicos. ${ }^{60}$

\subsection{Aplicación del derecho internacional humanitario a los contratistas privados a través de la elaboración de un tratado internacional}

El otro modelo de regulación de las actividades de las compañías militares y de seguridad privadas es a través de un tratado internacional de carácter multilateral. La elaboración de un instrumento convencional, de alcance regional o universal, resulta el medio más idóneo para someter sus actividades a controles jurídicos y asegurar la rendición de cuentas, lo que sin duda contribuye a reforzar la obligatoriedad del derecho internacional humanitario para estas empresas. Dicha reglamentación debe establecer los compromisos a los que están sometidos los Estados implicados o afectados por la utilización de estos contratistas privados y debe promover la cooperación entre todos ellos, en la medida en que tales compañías suelen prestar sus servicios en el extranjero y a menudo en países que carecen de capacidad para aplicar su propia legislación interna. ${ }^{61}$

59 Por eso, como ha afirmado oportunamente el Grupo de Trabajo sobre la Utilización de Mercenarios, estos códigos de conducta no pueden suplir la ausencia o insuficiencia de una legislación estatal o internacional adecuadas. Ver A/68/339, párr. 65, p. 18.

60 En este sentido, ver Gómez del Prado, José Luis \& Torroja Mateu, Helena, Hacia la regulación internacional de las empresas militares y de seguridad privadas, Marcial Pons, Madrid, 2011, pp. 59-60; Laborie, La privatización..., op. cit., p. 216. Así, resulta totalmente pertinente la proclamación que se hace en el preámbulo de proyecto de una posible convención sobre las empresas militares y de seguridad privadas (EMPS) cuando afirma que "la autorregulación de las empresas militares y de seguridad privadas no es suficiente para garantizar el respeto del derecho internacional humanitario y las normas internacionales de derechos humanos por parte del personal de estas empresas" y que "una protección eficaz requiere legislación nacional e internacional apropiada con miras a la adopción y la puesta en marcha de mecanismos que garanticen el cumplimiento". Ver A/HRC/15/25, pp. 21-22.

61 Así, en la Recomendación 1858 (2009), aprobada por la Asamblea Parlamentaria del Consejo de Europa el 29 de enero de 2009, se considera que la elaboración de un marco legal internacional es el medio más idóneo para fiscalizar las actividades de estas empresas a tenor del carácter trasnacional de los servicios que prestan, pues permitiría el establecimiento de estándares uniformes y facilitaría la cooperación internacional. Se evitaría, además, que 
Además de la propuesta de un posible tratado europeo, planteada por la Asamblea Parlamentaria del Consejo de Europa en su Recomendación 1858 (2009), se debe destacar el Proyecto de una posible convención sobre las empresas militares y de seguridad privadas (EMPS), elaborado por el Grupo de Trabajo sobre la Utilización de Mercenarios en 2010, en el que se establecen unas normas internacionales mínimas que los Estados deberán tener en cuenta para la regulación de estas entidades. ${ }^{62}$ Este nuevo instrumento pretende ofrecer una respuesta jurídica que permita sortear los obstáculos que hasta ahora han impedido la aplicación de las legislaciones nacionales a estas empresas, especialmente cuando prestan sus servicios en un Estado extranjero, así como superar las dificultades para investigar violaciones de los derechos humanos y del derecho internacional humanitario en zonas de conflicto, y exigir las distintas responsabilidades que se puedan derivar de la actuación de los contratistas privados. ${ }^{63}$ De este modo, el proyecto de convención trata de favorecer la supervisión de las actividades de estas empresas y la rendición de cuentas, a tenor de la naturaleza de los servicios que prestan, imponiendo a tal efecto obligaciones a los Estados implicados. Para alcanzar este objetivo, el marco legal al que deben someterse los contratistas privados se asienta sobre tres grandes pilares: i) A partir del principio del monopolio estatal del uso legítimo de la fuerza, se definen las funciones que deben ser consideradas inherentes al Estado y que no pueden dejarse en manos privadas o externalizarse. ${ }^{64}$ ii) Se establece una serie de obligaciones

eludan las posibles legislaciones estatales más estrictas cambiando su sede social a otro país cuya normativa resulte más permisiva. Por su parte, la Asamblea General de las Naciones Unidas ha mantenido esta misma postura en su Resolución 67/159, del 20 de diciembre de 2012.

${ }^{62} \mathrm{Al}$ respecto, ver Ballesteros Moya, Vanessa, "Las empresas militares y de seguridad privadas como entidades que ejercen prerrogativas públicas a efectos de la responsabilidad internacional de Estado", Revista Electrónica de Estudios Internacionales, 2013, (25), p. 23, en http://www.reei.org/index.php/revista/num25, consulta de septiembre 12 de 2014).

63 Ver Gómez del Prado\& Torroja Mateu, Hacia la regulación..., op. cit., pp. 74-75.

64 El proyecto define en su artículo $2^{\circ}$, i) las funciones inherentes al Estado como "las funciones acordes con el principio del monopolio del uso legítimo de la fuerza por parte del Estado, que los Estados no pueden contratar externamente o delegar en las EMSP en ninguna circunstancia". Entre estas funciones, cuya delegación y/o externalización está prohibida según el artículo $9^{\circ}$, se incluyen la participación directa en las hostilidades, las operaciones militares, la captura de prisioneros, la legislación, las tareas de espionaje, inteligencia y transferencia de conocimientos con aplicaciones militares, de seguridad y policiales, el uso de armas de destrucción en masa y el ejercicio de funciones de policía y otras actividades conexas, 
dirigidas a los Estados para que creen un régimen nacional de regulación, supervisión y control de los contratistas privados: este sistema se basa en la concesión de licencias y en el registro de estas empresas, a través del cual se limita, controla y supervisa su actuación, ${ }^{65}$ y se complementa con un mecanismo de control internacional integrado por el Comité de Regulación, Supervisión y Control de las Empresas Militares y de Seguridad Privadas (art. 29) y el registro internacional de estas empresas (art. 30). iii) Además, el proyecto incorpora obligaciones para los Estados dirigidas a favorecer la exigencia de responsabilidad a estas empresas y a sus empleados en caso de que incumplan, entre otras, las normas de derechos humanos.

Al referirse particularmente a la aplicación del derecho internacional humanitario, el proyecto destaca en su preámbulo que "la responsabilidad por las violaciones del derecho internacional humanitario y de los derechos humanos puede imputarse no sólo a los Estados sino también a las organizaciones intergubernamentales y agentes no estatales, incluidas las empresas militares y de seguridad privadas". Pero, a pesar de esta proclamación general, el proyecto, como sabemos, únicamente impone obligaciones de los Estados y, en consecuencia, solo sería aplicable indirectamente a dichas empresas y a sus empleados. ${ }^{66}$ Así se desprende del ámbito de aplicación definido por el artículo $3^{\circ}$, que se circunscribe a los Estados y las organizaciones internacionales, excluyendo a las empresas como destinatarios directos de sus normas. Además, todas las obligaciones contenidas en el proyecto de convención relacionadas con el respeto del derecho internacional humanitario corren a cargo de los Estados, que deberán velar por su cumplimiento por parte de los contratistas privados, debiendo adoptar a tal efecto las medidas oportunas. ${ }^{67}$

especialmente las facultades de arresto o detención, incluida la de interrogar a los detenidos y otras funciones que un Estado parte considere funciones inherentes al Estado.

65 Ver Gómez del Prado \& Torroja Mateu, Hacia la regulación..., op. cit., p. 96.

66 En este sentido, ver Laborie, La privatización..., op. cit., pp. 180-181.

${ }^{67}$ Un repaso del proyecto de convención refleja que son los Estados los que deben asumir la totalidad de las obligaciones en relación con las actividades de las compañías militares y de seguridad privada, sometiéndoles a una estrecha tutela estatal que contrasta acusadamente con la amplia libertad y capacidad de acción de que disfrutan en estos momentos. Así, deben asegurarse de que las empresas militares y de seguridad privada reciban formación en materia de derecho internacional humanitario $\left(\operatorname{art} .4^{\circ}, 2\right)$ y de que estas empresas y su personal desempeñen sus funciones de acuerdo con las normas de derecho internacional humanitario (art. $\left.5^{\circ}, 1\right)$; deberán adoptar las medidas necesarias para asegurar que las empresas y sus empleados sean responsables de las violaciones del derecho internacional humanitario 
Al margen del papel relevante que deben jugar los Estados, hubiera resultado pertinente incluir expresamente en el proyecto de convención obligaciones a cargo de las empresas en relación con el respeto del derecho internacional humanitario. ${ }^{68}$

Sin embargo, aunque este ambicioso texto puede contribuir al respeto del ius in bello, no parece que los Estados más interesados -especialmente los occidentales- tengan la voluntad de promover la creación un instrumento de esta naturaleza para regular las actividades de dichas empresas, y menos aún con las estrictas obligaciones de supervisión que pretende imponerles. ${ }^{69}$ Así se refleja en las conclusiones aprobadas en la reciente Conferencia Montreux +5, celebrada el 13 de diciembre de 2013 bajo el patrocinio del gobierno suizo y del Comité Internacional de la Cruz Roja, para evaluar la aplicación del Documento de Montreux. En ellas, se ha destacado que "[t]his multi-layered approach, combining soft law instruments, self-regulatory instruments and national legislation is innovative and has proven to be both effective and efficient", abogándose, incluso, por la extensión de este modelo regulatorio a otros ámbitos. ${ }^{70}$

(art. $\left.7^{\circ}, 1\right)$; deberán garantizar que estas empresas y su personal aseguren que sus actividades no contribuyan a la violación del derecho internacional humanitario (art. $7^{\circ}, 2$ ); adoptarán medidas para impedir que las empresas utilicen armas prohibidas (art. 10); o investigarán las denuncias de violaciones del derecho internacional humanitario cometidas por estas empresas y garantizarán el castigo de los culpables (art. 13, 5).

68 Sin embargo, aunque en nuestra opinión hubiera resultado oportuno, no es objeto del proyecto identificar obligaciones directas para las empresas militares y de seguridad privadas. Ver Gómez del Prado \& Torroja Mateu, Hacia la regulación..., op. cit., p. 98.

69 Esta falta de interés por la elaboración de un convenio internacional se puso de manifiesto en el primer período de sesiones del grupo de trabajo intergubernamental de composición abierta encargado de estudiar la posibilidad de elaborar un marco normativo internacional para la regulación, el seguimiento y la supervisión de las actividades de las empresas militares y de seguridad privadas (23 a 27 de mayo de 2001). Algunas delegaciones, como la de la Unión Europea, Gran Bretaña, Suiza, Estados Unidos o España, destacaron su preferencia por otras formas de regulación -especialmente el Código Internacional de Conducta- frente al proyecto de convención propuesto por el grupo de trabajo. Ver Resumen del primer período de sesiones del grupo de trabajo intergubernamental de composición abierta encargado de estudiar la posibilidad de elaborar un marco normativo internacional para la regulación, el seguimiento y la supervisión de las actividades de las empresas militares y de seguridad privadas, Doc. A/HRC/WG.10/1/4, 22 de noviembre de 2011, pp. 16-18.

70 FDFA/ICRC, Montreux+5 Conference. Chairs' conclusions. Geneva, 13 December 2013, en https://www.icrc.org/eng/assets/files/2014/montreux-plus-5-conclusions-12-2013.pdf, consulta de septiembre 11 de 2014. 
Esta conclusión parece dejar el interés por la elaboración de un tratado internacional en un plano muy secundario. ${ }^{71}$

\subsection{Otras formas de regulación que permiten promover el respeto del derecho internacional humanitario por las compañías militares y de seguridad privadas}

Junto a los intentos de regulación internacional de las actividades de las compañías militares y de seguridad privadas, la obligatoriedad del derecho internacional humanitario para los contratistas privados puede encontrar su fundamento en el derecho interno del Estado en el que tienen su sede social o en el que operen. Estas compañías, como cualquier entidad privada que desee constituirse dentro de un Estado, deben respetar las condiciones previstas en su legislación, entre las cuales se encontrará la observancia del derecho nacional aplicable. Lo mismo se puede decir en relación con las que presten sus servicios en el territorio de otro Estado. ${ }^{72}$ De este modo, las compañías y sus empleados deben cumplir las normas de derecho internacional humanitario que les imponga el derecho interno. ${ }^{73}$

Para ello, es importante que los Estados aprueben leyes en las que regulen los servicios que pueden prestar -incluso en el extranjero-, que enuncien claramente las obligaciones a las que están sometidas y que prevean las consecuencias de su incumplimiento, así como mecanismos de supervisión y control. ${ }^{74}$ Sin embargo, en la práctica se constata que existen

\footnotetext{
71 Sin embargo, alguno de los participantes señaló la utilidad de negociar un instrumento de este tipo para regular de forma más efectiva aspectos relacionados con la jurisdicción y la asistencia judicial mutua para favorecer la persecución de los responsables de infracciones de los derechos humanos y del derecho internacional humanitario, pues "pp]roviding effective remedies and accountability is crucial to ensuring that the regulation of the PMSC industry is both legitimate and credible". Ibíd.

72 En algunas legislaciones estatales, se establece un régimen de licencias para poder operar en su territorio, lo que puede ser un procedimiento adecuado para promover el respeto del derecho internacional humanitario por parte de estas empresas. A favor de esta opción se han pronunciado el Consejo de Europa en la Recomendación 1858 (2009) y el Grupo de Trabajo sobre la Utilización de Mercenarios, tal como se refleja en el proyecto de convención (art. 14).

73 Así figura en el Documento de Montreux (A/63/467-S/2008/636, párr. 22, p. 11). Para los Estados Unidos, "It]he law of war obligations of the United States are observed and enforced by the DoD Components and DoD contractors assigned to or accompanying deployed Armed Forces". Department of Defense, Directive No 2311.01E, DoD Law of War Program, May 9, 2006, par. 4.2.

74 Ver Pozo Serrano, Pilar, "Las compañías de seguridad privadas como nuevo actor en el
} 
grandes divergencias en el nivel de regulación estatal de las actividades de estas empresas, lo que da lugar a incoherencias y carencias. ${ }^{75}$ Adicionalmente, la eficacia de estas disposiciones dependerá de que los Estados posean la capacidad necesaria para asegurar su cumplimiento, lo que no suele ocurrir en la mayoría de los escenarios en los que prestan sus servicios estas empresas, caracterizados por la debilidad de las instituciones políticas y judiciales, como en Sierra Leona, Afganistán e Irak. De ahí el importante papel que debe jugar el Estado en cuyo territorio tiene su sede social la compañía, según se reconoce en el Documento de Montreux. ${ }^{76}$

Los contratos también pueden ser un instrumento útil para promover la aplicación del derecho internacional humanitario. La inclusión de una cláusula contractual debidamente redactada en la que se exija el pleno respeto de este tipo de obligaciones y que establezca plenas garantías de cumplimiento de estas a la hora del reclutamiento de nuevos empleados, que requiera la debida instrucción del personal que vaya a prestar los servicios contratados y que demande de la empresa el establecimiento de un sistema de disciplina interno puede incentivar a estas compañías a respetar dichas normas. ${ }^{77}$ En esta línea, el Documento de Montreux recoge entre las buenas prácticas para los Estados contratantes que se incluyan cláusulas que aseguren el respeto del derecho internacional humanitario por parte de la empresa o que permitan

ámbito de la paz y la seguridad internacionales: actividades y marco jurídico", en Blanc Altemir, A. (ed.), Elproceso de reforma de las Naciones Unidas. La dimensión institucional y el mantenimiento de la pazy la seguridad internacionales, Tecnos, Madrid, 2009, p. 391.

75 Así lo ha constatado el Grupo de Trabajo sobre la Utilización de Mercenarios en un análisis de la práctica de trece Estados africanos. Ver Informe anual del Grupo de Trabajo sobre la Utilización de Mercenarios como medio de violar los derechos humanos y obstaculizar el ejercicio del derecho de los pueblos a la libre determinación, Doc. A/HRC/24/45, $1^{\circ}$ de julio de 2013, párr. 24, p. 7.

76 A/63/467-S/2008/636, p. 10. Sin embargo, se constata que la legislación de muchos Estados no es lo suficientemente clara sobre su aplicación extraterritorial, esto es, cuando las empresas operen en el extranjero. Esta carencia dificulta la aplicación del derecho interno, sobre todo en casos de denuncias de violaciones del derecho internacional humanitario. Ver Buckland, Benjamin S. \& Burdzy, Anna Marie, Progress and opportunities, five years on: challenges and recommendations for Montreux Document endorsing States, DCAF, Geneva, 2013, pp. 21-23.

77 En este sentido, ver Clapham, "Human rights...", op. cit., p. 517. Así figura, aunque de una manera muy difusa, en el acuerdo del 31 de enero de 1997 entre Papúa Nueva Guinea y Sandline International, en el que se establece que "at no time will Sandline personnel cater the sovereign territory of another nation nor will they breach the laws and rules of engagement relating to armed conflicts". Sobre el contrato como un instrumento para promover el respeto del ius in bello, ver Dickinson, Laura, "Public law values in a privatized world", Yale Journal of International Law, 2006, 31, pp. 401-425. 
exigir que la conducta de toda empresa subcontratada sea conforme al derecho internacional humanitario, pudiéndose también prever que, en caso de incumplimiento de estas cláusulas, el contrato pueda ser rescindido. ${ }^{78}$ Pero este incumplimiento podría acarrear otro tipo de consecuencias para la empresa dependiendo de las sanciones que prevea la legislación del Estado contratante para este tipo de infracciones, como la pérdida de la licencia para operar en el país o en el extranjero, la inhabilitación temporal o permanente para volver a obtener contratos con el Estado, la inclusión en un registro de empresas incumplidoras.

Estas medidas solo serán efectivas si el Estado acepta imponer cláusulas de este tipo en los contratos que firme con las empresas, si está en condiciones de controlar su ejecución, incluido el respeto de estas obligaciones, y si está dispuesto a adoptar sanciones en caso de infracción, como las indicadas anteriormente. Sin embargo, en la práctica no se observa que los Estados contratantes sean especialmente rigurosos con las empresas con antecedentes de violaciones de los derechos humanos. ${ }^{79}$ A ello hemos de sumar la falta de transparencia que rodea, en la mayoría de los casos, al contenido de los contratos y la ausencia de una supervisión eficaz de su ejecución. ${ }^{80}$ Además de estos problemas prácticos, se corre el riesgo de que

78 Ver A/63/467-S/2008/636, párrs. 14-15, p. 17.

79 A este respecto, el ejemplo de los Estados Unidos es significativo, pues en junio de 2010 el gobierno otorgó a Xe Services (antigua Blackwater y actualmente Academi) nuevos contratos por valor de unos 220 millones de dólares para proteger las instalaciones en Afganistán y en otros lugares, y para prestar servicios de protección a la CIA, a pesar de sus antecedentes de falta de respeto de los derechos humanos y del derecho internacional humanitario, lo cual contradice el compromiso de este país de promover el respecto de estas normas por parte de las empresas militares y de seguridad privadas, tal como se deriva del Documento de Montreux y del Código Internacional de Conducta para Proveedores de Servicios de Seguridad Privada. Ver Informe del Grupo de Trabajo sobre la Utilización de Mercenarios como medio de violar los derechos bumanos y obstaculizar el ejercicio del derecho de los pueblos a la libre determinación, Doc. A/65/325, 25 de agosto de 2010, párr. 10-11, p. 6.

80 En el informe sobre los abusos y torturas en la cárcel de Abu Ghraib, se constató la falta de supervisión adecuada de los contratistas privados implicados en estos crímenes: "In general, us civilian contract personnel (Titan Corporation, CACI, etc.), third country nationals, and local contractors do not appear to be properly supervised within the detention facility at Abu Ghraib. During our on-site inspection, they wandered about with too much unsupervised free access in the detainee area. Having civilians in various outfits (civilian and DCUs) in and about the detainee area causes confusion and may have contributed to the difficulties in the accountability process and with detecting escapes". Major General Antonio M. Taguba, Article 15-6 Investigation at the 800th Military Police Brigade, p. 26, en http:// www.npr.org/iraq/2004/prison_abuse_report.pdf, consulta de noviembre 25 de 2013. 
la aplicación del derecho internacional humanitario quede reducida a una mera cuestión contractual, cuyo incumplimiento quedaría en manos de los mecanismos de arreglo de disputas comerciales. ${ }^{81}$ Por las dificultades apuntadas, aunque esta opción pueda ofrecer ciertas ventajas para la aplicación del derecho internacional humanitario, no constituye un medio idóneo de promover el respeto de estas normas. ${ }^{82}$

\section{Fortalecimiento del respeto del derecho internacional humanitario a través del reconocimiento de la responsabilidad de los directivos y supervisores de las compañías militares y de seguridad privadas}

Una de las consecuencias de la aplicación del derecho internacional humanitario a las compañías militares y de seguridad privadas es que las violaciones más graves de dichas normas acarrean la responsabilidad penal internacional de quienes las cometan. Como es sabido, esta responsabilidad no se circunscribe a los agentes estatales, sino que también se extiende a cualquier otra persona que participe activamente en las hostilidades. Para este sector normativo, la sanción a quienes hayan cometido crímenes de guerra debe aplicarse sin ningún tipo de distinción derivada de su calificación como combatientes o civiles. ${ }^{83}$ Nadie puede quedar así exonerado de responsabilidad por el mero hecho de pertenecer o no a una de estas categorías. ${ }^{84}$ Sobre la base de estas premisas, el ambiguo estatuto jurídico del personal de estas empresas no influye en su posible responsabilidad -aunque en la práctica ha dificultado su enjuiciamiento-,${ }^{85}$ pudiendo ser perseguidos con inde-

\footnotetext{
81 Ver Lapointe, «Le droit international... », op. cit., p. 99.

82 Así se lo ha planteado el Comité sobre Actores no Estatales creado por la International Law Association en su informe preliminar de 2008, en http://www.ila-hq.org/en/committees/index.cfm/cid/1023, consulta de octubre 15 de 2013.
}

$83 \mathrm{Al}$ respecto, ver Henckaerts \& Doswald-Beck, El derecho internacional..., op. cit., pp. 648649.

84 En efecto, como afirmó el TPIR, "international humanitarian law would be lessened and called into question if it were to be admitted that certain persons be exonerated from individual criminal responsibility for a violation of common article $3^{\circ}$ under the pretext that they did not belong to a specific category". The Prosecutor v. Jean-Paul Akayesu..., op. cit., par. 443. En la doctrina, ver Pérez-León Acevedo, Juan Pablo, La responsabilidad internacional del individuo por crimenes de guerra, ARA Editores, Lima, 2008, pp. 358-359.

85 En este sentido, ver Lehnardt, Chia, "Individual liability of private military personnel under international criminal law", European Journal of International Law, 2008, 19, (5), p. 1016. 
pendencia de que sean considerados como combatientes o civiles, siempre y cuando su comportamiento esté conectado con el escenario bélico en el que prestan sus servicios. ${ }^{86}$

Esta circunstancia constituye sin duda un aliciente para el respeto del derecho internacional humanitario por parte de los contratistas privados, ${ }^{87}$ pero también va a influir en la forma en que operan, pues, igual que ocurre con cualquier grupo o entidad que tome parte en un conflicto armado, el deber de cumplir las obligaciones derivadas de tales normas va a requerir que dispongan de una estructura interna. A tal efecto, deben dotarse de un esquema de autoridad o un liderazgo con capacidad para ejercer un control efectivo sobre sus empleados que garantice el cumplimiento de sus instrucciones, aunque no tiene que ser equivalente al de las fuerzas armadas. ${ }^{88}$

Dentro de esta estructura organizativa interna, corresponde a los directivos, administradores o supervisores garantizar que el personal a su cargo respete el derecho internacional humanitario en el desempeño de las tareas que se les hayan encomendado y a tal efecto deberán adoptar las medidas necesarias y razonables en caso de que cometan alguna infracción. ${ }^{89}$ La empresa asume así el deber de respetar tales normas y de asegurar su cumplimiento por parte de sus empleados, ${ }^{90}$ pues, a través de la figura de

86 Ver Cameron, Lindsey \& Chetail, Vincent, Privatizing war. Private military and security companies under public international law, Cambridge University Press, Cambridge, 2013, pp. 80-81.

87 Ver Clapham, “Human rights...”, op. cit., p. 518.

88 Para valorar este requisito, habrá que tener en cuenta criterios como la existencia de un cuartel general; la capacidad para llevar a cabo operaciones de forma organizada; la capacidad de adquirir, transportar y distribuir armas; estar dotado de una estructura de mando, normas disciplinarias y mecanismos para su exigencia; la existencia de un sistema de reclutamiento, entrenamiento, estrategia y tácticas militares; y la capacidad del grupo para hablar con una sola voz. Ver Trial Chamber II, The Prosecutor v. Ljube Boškoski, Johan Tarčulovski, Case IT-04-82-T, Judgement of 10 July 2008, pars. 196-203. En la doctrina, ver Paulus, Andreas \& Vashakmadze, Mindia, "Asymmetrical war and the notion of armed conflict - a tentative conceptualization", International Review of the Red Cross, 2009, 91, (873), pp. 117-118.

89 Así se deriva del Código Internacional de Conducta para Proveedores de Servicios de Seguridad Privada, en virtud del cual "[1]as empresas firmantes cumplirán y exigirán a su personal que cumpla las leyes aplicables, incluidos el derecho internacional humanitario y las normas de derechos humanos que les sean impuestas por la legislación nacional pertinente, así como cualquier otra legislación nacional e internacional aplicable" (párr. 21).

$90 \quad$ Así lo ha reconocido el TPIY con carácter general, pero que es aplicable a las compañías militares y de seguridad privadas, como pondremos de relieve a continuación: "The principle of command responsibility may be seen in part to arise from one of the basic principles of international bumanitarian law aiming at ensuring protection for protected categories of persons and objects during armed 
la responsabilidad del superior jerárquico, la no adopción de medidas para impedir este tipo de comportamientos delictivos no solo afectará al buen nombre de la compañía, sino también acarreará la responsabilidad penal de sus directores y administradores. ${ }^{91}$ En efecto, como se señala en el Documento de Montreux, estos cargos directivos podrán ser considerados responsables por los crímenes cometidos por las personas "que estén bajo su autoridad y control efectivos cuando no hayan ejercido el control necesario"..$^{92}$ Nuevamente esta disposición figura en la parte del texto dedicada a las obligaciones jurídicas de estas empresas, lo que pone de manifiesto que la exigencia de responsabilidad a sus directivos ya constituye una norma en vigor en el derecho internacional humanitario.

La jurisprudencia de los tribunales penales internacionales ha venido a confirmar esta interpretación, pues, aunque no ha abordado específicamente la situación de los directivos y administradores de las compañías militares y de seguridad privadas, ha elaborado una noción de superior jerárquico lo suficientemente amplia como para adaptarse a la realidad de los conflictos

conflicts. This protection is at the very heart of international humanitarian law. Ensuring this protection requires, in the first place, preventative measures which commanders are in a position to take, by virtue of the effective control which they have over their subordinates, thereby ensuring the enforcement of international bumanitarian law in armed conflict. A commander who possesses effective control over the actions of his subordinates is duty bound to ensure that they act within the dictates of international humanitarian law and that the laws and customs of war are therefore respected". 'Trial Chamber, The Prosecutor v. Sefer Halilovic, Case IT-01-48-T, Judgement of 16 November 2005, par. 39.

91 Se ha reconocido tradicionalmente en el derecho internacional humanitario -constituyendo en la actualidad una norma consuetudinaria, tal como se establece en la Regla 153 del Estudio del CICR sobre el derecho internacional humanitario consuetudinario- que los comandantes y otros mandos superiores son responsables de los crímenes de guerra cometidos por sus subordinados si sabían, o deberían haber sabido, que estos iban a cometer o estaban cometiendo tales crímenes y no tomaron todas las medidas razonables y necesarias a su alcance para evitar que se cometieran o, si ya se habían cometido, para castigar a los responsables. Para que exista esta responsabilidad del superior jerárquico, deben concurrir, por lo tanto, las siguientes condiciones: que se trate de un superior o persona con autoridad sobre sus subordinados; que el superior supiera o debería haber sabido que el crimen se iba a cometer o se estaba cometiendo; que el superior posea la autoridad necesaria para impedir o hacer cesar la conducta criminal; y que no haya adoptado las medidas necesarias y razonables a su alcance para prevenir o castigar la comisión de esos actos. Ver Henckaerts \& DoswaldBeck, El derecho internacional..., op. cit., p. 632.

92 Ver A/63/467-S/2008/636, párr. 27, p. 12. Así figura también en el artículo $7^{\circ}, 3$ del proyecto de convención sobre las empresas militares y de seguridad privadas. Ver A/HRC/15/25, p. 26. 
armados actuales. ${ }^{93}$ No se limita esta responsabilidad únicamente a los comandantes militares, sino que se extiende también a funcionarios civiles o líderes políticos y a otro tipo de personas que reúnan los requisitos básicos para aplicarles esta figura. ${ }^{94}$

Este enfoque amplio de la figura del superior jerárquico también se deriva del Estatuto de la Corte Penal Internacional, del 17 de julio de 1998, ${ }^{95}$ así como de la propia jurisprudencia de la Corte, que, al definir en el caso Bemba la noción de persona que "actúe efectivamente como jefe militar", ha afirmado que "this category of military-like commanders may generally encompass superiors who have authority and control over regular government forces such as armed police units or irregular forces (non-government forces) such as rebel groups, paramilitary units including, inter alia, armed resistance movements and militias that follow a structure of military hierarchy or a chain of command". "A A tenor de esta amplia interpretación del artículo 28a) del Estatuto, se podría llegar a entender que los

93 En efecto, esta noción amplia de superior jerárquico responde mejor a las características de muchos conflictos armados actuales, en los que, como se reconoce en el caso Naletilic, "only de facto, selfproclaimed governments with their de facto armies and paramilitary groups take part". Trial Chamber, The Prosecutor v. Mladen Naletilic, aka 'Tuta' and Vinko Martinovic, aka 'Śtela', Case IT-98-34-T, Judgement of 31 March 2003, par. 67.

94 Como ha afirmado el TPIY en el caso Boskoski, esta figura es aplicable no solo a los comandantes militares, sino también a los superiores civiles, que incurren en la misma responsabilidad penal que los primeros. The Prosecutor v. Ljube Boskeski..., op. cit., par. 409. En esta misma línea, el Tribunal Especial de Derechos Humanos de Timor Oriental señaló en el asunto Abilio Soares que "the responsibility of a superior could also include non-military superiors. This indicates that in certain cases analogies may be made between the responsibility of a military command and the responsibility of a non military superior or a civilian official. As additional legal basis, article 86 Additional Protocol I to the 1949 Geneva Convention in 1977, stipulates that in certain cases all superiors shall be responsible for failure to act". The Ad Hoc Human Rights Tribunal at the Human Rights Court of Justice of Central Jakarta, José Abilio Osório Soares, Case 01/PID.HAM/AD.Hoc/2002/ ph.JKT.PST, Judgement, 7 August, 2002,en http://www.internationalcrimesdatabase.org/ Case/41/Soares-(Abilio), consulta de octubre 6 de 2014.

95 El artículo 28 del Estatuto de la Corte Penal Internacional se refiere a los comandantes militares y a los superiores civiles cuando habla del "jefe militar o el que actúe efectivamente como jefe militar" en el apartado a) y de otras "relaciones entre superior y subordinado" distintas de las anteriores, en el apartado b). Ver Fenrick, William J., "Article 28. Responsibility of commanders and others superiors", in Triffterer, O. (ed.), Commentary on the Rome Statute of International Criminal court. Observers' notes, article by article, Nomos Verlagsgesellschaft, BadenBaden, 1999, p. 521.

96 Pre-Trial Chamber II, The Prosecutor v. Jean-Pierre Bemba Gombo, Case ICC-01/05-01/08, Decision pursuant to article 61(7) (a) and (b) of the Rome Statute on the charges of the Prosecutor against Jean-Pierre Bemba Gombo, 15 June 2009, par. 410. 
directivos, administradores o supervisores de algunas compañías militares y de seguridad privadas no son simplemente superiores civiles, sino podrían entrar dentro de la categoría de personas que actúan como jefe militares, pues, como la propia Corte ha señalado, "It]he notion of a military commander under this provision also captures those situations where the superior does not exclusively perform a military function". ${ }^{97}$ En efecto, muchas de estas empresas, a tenor de los servicios que prestan -especialmente cuando son de carácter armado-, requieren de una organización, de una estructura jerárquica y de una cadena de mando de carácter cuasimilitar que las acerca en su funcionamiento a las unidades militares. ${ }^{98}$

El elemento decisivo es la capacidad del superior para ejercer el mando, autoridad o control efectivos sobre las actividades de sus subordinados, más que el rango o la naturaleza del cargo desempeñado. ${ }^{99}$ Ello significa que dispone del poder suficiente para prevenir la comisión de crímenes por sus subordinados o para tomar medidas que permitan sancionar ese comportamiento. ${ }^{100}$ Pero no es necesario que este control se ejerza de forma directa sobre el subordinado, sino que puede hacerse a través de la cadena

97 Ibíd., par. 408.

98 En este sentido, ver Lehnardt, "Individual liability...”, op. cit., p. 1026. Esto se podría aplicar a empresas del tipo de Executive Outcomes, de la que se ha afirmado que "constituía una fuerza armada privada autónoma y completa. Era completa porque ofrecía reproducir toda la cadena de servicios militares, desde las unidades de combate y el know-how estratégicomilitar (instrucción y asesoramiento) hasta la logística. Además era autónoma porque disponía de un armamento, un sistema de reconocimiento y un sistema de transporte propios". En definitiva, "[q]uien contrataba a Executive Outcomes obtenía los servicios de una pequeña fuerza armada moderna con amplia experiencia, económica y eficiente". Uesseler, Rolf, La guerra como negocio. Cómo las empresas militares privadas destruyen la democracia, Belacqva, Barcelona, 2007, pp. 79-81.

99 Es irrelevante, además, si la relación superior-subordinado es de iure o de facto. Así lo confirma la jurisprudencia del TPIY en los casos Celebici (Appeals Chamber, The Prosecutor $v$. Zejnil Delalic..., op. cit., par. 196) o Aleksovski (Trial Chamber, The Prosecutorv. Zlatko Aleksovski, Case IT-95-14/1-T, Judgement of 25 June 1999, pars. 76-78). Ver Williamson, Jamie Allan, "Some considerations on command responsibility and criminal liability", International Review of the Red Cross, 2008, 90, (870), pp. 306-307.

100 En el caso de los superiores civiles, no se requiere que dispongan de poder para sancionar las infracciones cometidas por sus subordinados, basta con que se informe de ello a las autoridades competentes para que estas tomen las medidas adecuadas. Así lo ha reconocido el TPIY en el caso Aleksovki (The Prosecutorv. Zlatko Aleksovski..., op. cit., par. 78). Ver Nerlich, Volker, "Superior responsibility under article 28 ICC Statute. For what exactly is the superior held responsible?", Journal of International Criminal Law, 2007, 5, (3), pp. 669-670. 
de mando. ${ }^{101}$ Por eso, la responsabilidad no se limitaría a los supervisores que actúan sobre el terreno, sino que se puede extender a los directivos de las empresas que dispongan de capacidad para prevenir o sancionar tales comportamientos delictivos.

Asimismo, se requiere que el superior conociera o tuviera motivos para conocer que sus subordinados cometieron o iban a cometer actos criminales y no adoptó las medidas necesarias y razonables para prevenirlos o castigarlos. ${ }^{102} \mathrm{Si}$ bien, tradicionalmente, el grado de 'conocimiento' que se exigía a un superior con respecto a las acciones de sus subordinados era el mismo tanto para los comandantes militares como para los otros superiores, ${ }^{103} \mathrm{en}$ el artículo 28 del Estatuto de la Corte Penal Internacional se distingue a los jefes militares o a las personas que actúen efectivamente como tales de los superiores civiles. ${ }^{104}$ Así, los primeros son responsables cuando hubieren

101 Así se ha pronunciado el TPIY en el caso Oric. Trial Chamber II, The Prosecutor v. Naser Oric, Case ${ }^{\circ}$ IT-03-68-T, Judgement of 30 June 2006, par. 311.

102 Este requisito se cumple cuando los superiores, militares o civiles, tienen un conocimiento directo de que se van a cometer o se han cometido los crímenes o, al menos, cuando cuenten con cierta información que los advierta acerca de la probable comisión de violaciones del derecho internacional humanitario por sus subordinados. Trial Chamber II, The Prosecutor $v$. Zejnil Delalic..., op. cit., par. 383. La interpretación dada a este requisito por la jurisprudencia del TPIY parece decantarse por la negligencia grave para todo superior jerárquico. Al respecto, Ver Henzelin, Marc, «Les 'raisons de savoir' du supérieur hiérarchique qu’un crime va être commis ou a été commis par un subordonné. Examen de la jurisprudence des Tribunaux pénaux internationaux pour l'ex-Yougoslavie et le Rwanda », in Tavernier, P. (dir.), Actualité de la jurisprudence pénale internationale à l'heure de la mise en place de la Courpénale internationale, Bruylant, Bruxelles, 2004, p. 123.

103 Así se refleja en los Estatutos del TPIY (art. $7^{\circ}, 3$ ), del TPIR (art. $6^{\circ}, 3$ ) o del Tribunal Especial para Sierra Leona $\left(\operatorname{art} .6^{\circ}, 3\right)$, en los cuales no se diferencia entre la responsabilidad del jefe militar y la de otros superiores jerárquicos. Al respecto, ver Williamson, "Some considerations...", op. cit., p. 307.

104 Este enfoque fue adoptado por el TPIR -frente a la jurisprudencia anterior del propio Tribunal y del TPIY- en los casos Kayishema \& Ruzindana al delimitar el significado de la expresión "tenía razones para saber", contenida en el artículo 6 3 , 3 de su Estatuto con respecto a jefes no militares, basándose en el artículo 28 del Estatuto de la Corte Penal Internacional. Trial Chamber II, The Prosecutor v. Clément Kayishema and Obed Ruz̨indana, Case ICTR-95-1-T, Judgement of 21 May 1999, pars. 227-228. Sin embargo, en el caso Musema, el Tribunal vuelve a rechazar esta diferenciación entre superiores jerárquicos militares y civiles. Trial Chamber I, The Prosecutor v. Alfred Musema, Case ICTR-96-13-A, Judgement and Sentence of 27 January 2000, pars. 147-148. Para un análisis de los cambios en la jurisprudencia del TPIR, ver Henzelin, "Les 'raisons de savoir'... », op. cit., pp. 89-120. 
sabido, o en función de las condiciones del momento, hubieren debido saber que las personas a su cargo estaban cometiendo esos crímenes o se proponían cometerlos, lo que significa que responden tanto por comportamientos dolosos como culposos. Por el contrario, otros superiores no militares solo responden en caso de conducta intencional -que incluye el dolo eventual-, consistente en haber tenido conocimiento o deliberadamente haber hecho caso omiso de información que indicase claramente que los subordinados estaban cometiendo estos crímenes o se proponían cometerlos. Además, se requiere que los crímenes guarden relación con las actividades bajo su autoridad y control efectivo. ${ }^{105}$

A tenor de la práctica, las compañías militares y de seguridad privadas, sobre todo las especializadas en proporcionar determinados servicios militares y de seguridad, como la protección armada de personas, instalaciones, edificios, convoyes u otros lugares, el mantenimiento y el manejo de sistemas de armamento, la custodia de prisioneros o la formación de personal militar o policial, disponen de una estructura jerárquica, una cadena de mando y un sistema de disciplina interna adecuados que facilitan el control de sus empleados y la adopción de medidas preventivas o represivas en relación con la aplicación del derecho internacional humanitario. ${ }^{106}$ Ello permitiría, como ya hemos avanzado, equiparar a los directivos, administradores o supervisores de muchas de estas empresas -aquellas que, como hemos dicho, son contratadas para prestar servicios armados que supongan una participación directa en las hostilidades-a los comandantes militares, de acuerdo con la definición

105 De este modo, en el caso de los superiores civiles, el estándar exigido es más estricto que para los superiores militares, pues debe demostrarse no solo que el superior contaba con información relacionada con los actos de sus subordinados, sino que deliberadamente hizo caso omiso de esa información, esto es, que eligió no tener en cuenta esa información y no actuar en respuesta a ella, lo que excluye el comportamiento negligente. Sobre esta cuestión, ver Rodríguez-Villasante y Prieto, José Luis, "La responsabilidad de los superiores jerárquicos militares y no militares a la luz de la legislación nacional del Estado de que se trate y de la experiencia internacional", en Olasolo Alonso, H. \& Cuenca Curbelo, S. (coords.), Perspectiva iberoamericana sobre la justicia penal internacional, vol. I, Tirant lo Blanch, Valencia, 2012, pp. 163164; Lirola Delgado, Isabel \& Martín Martínez, Magdalena M., La Corte Penal Internacional. Justicia versus impunidad, Ariel, Madrid, 2001, p. 147.

106 Quirico, “The criminal responsibility...”, op. cit., pp. 434-435. La existencia de una cadena de mando y un sistema de disciplina interna para asegurar el respeto del derecho internacional humanitario se deriva de los códigos de conducta que han elaborado algunas empresas del sector como Aegis. Ver Aegis Code of Conduct, August 2013, en http:/ /www.aegisworld.com/ compliance, consulta de octubre 6 de 2014. 
amplia contenida en la jurisprudencia de la Corte Penal Internacional. ${ }^{107}$ En el caso de otro tipo de contratistas privados que no lleven a cabo tales tareas, sus directivos encajarían mejor en la noción de superiores civiles contenida en el Estatuto de la Corte Penal Internacional. ${ }^{108}$

Por eso, es importante que los directivos o administradores de las compañías militares y de seguridad privadas garanticen este control interno, tomando las medidas pertinentes para asegurarse de que el personal a su cargo respete las normas del ius in bello. ${ }^{109}$ Entre las medidas que con carácter preventivo se podrán adoptar para evitar que los empleados vulneren estas reglas, se debe mencionar la existencia de procedimientos de selección de personal adecuados, que tengan en cuenta los posibles antecedentes de violaciones de los derechos humanos; establecer programas de formación e instrucción de los empleados en el derecho internacional humanitario, en la línea de la obligación de difusión impuesta a los comandantes militares en relación con el personal a sus órdenes (art. 87, 2 del Protocolo Adicional

107 En este sentido, ver Werle, Gerhard, Tratado de derecho penal internacional, $2^{\mathrm{a}}$ ed., Tirant lo Blanch, Valencia, 2011, p. 318.

108 Aunque esta diferenciación entre la responsabilidad de los superiores jerárquicos militares y civiles no parece contemplarse en el derecho consuetudinario (Henckaerts \& DoswaldBeck, El derecho internacional..., op. cit., pp. 632-636), se ha estimado que la equiparación de la responsabilidad de ambos tipos de superiores jerárquicos solo se podría justificar cuando el superior civil se encuentra de facto en la misma situación que el comandante militar. Por eso, se ha considerado en la doctrina que el tratamiento diferenciado de la responsabilidad de los superiores jerárquicos militares -incluidos los superiores civiles que se encuentran en la misma posición que los militares- y el resto de los civiles resulta más convincente. A favor de esta posición, ver Henzelin, "Les 'raisons de savoir'... », op. cit., pp. 123-124. Pero también ha sido objeto de críticas porque al establecer requisitos más estrictos podría dificultar la exigencia de responsabilidad a los superiores civiles y favorecer su impunidad. En este sentido, Ver Vetter, Greg R., "Command responsibility of non-military superiors in the International Criminal Court (ICC)”, Yale Journal of International Law, 2000, 25, (1), pp. 92-93.

109 En el Código Internacional de Conducta para Proveedores de Servicios de Seguridad Privada, las empresas "incorporarán este código a las políticas de la empresa, los sistemas de control interno y los sistemas de conformidad de la empresa y los integrarán en los elementos pertinentes de sus operaciones" (párr. 44). A partir de este compromiso general, en el código se recogen las medidas preventivas indicadas más arriba. Al respecto, ver Jerbi, Scott, The International Code of Conduct for Private Security Service Providers, Academy Briefing $\mathrm{N}^{\circ} 4$, Geneva Academy of International Humanitarian Law and Human Rights, August 2013, p. 45, en http://www.geneva-academy.ch/docs/publications/briefing4_web_final.pdf, consulta de septiembre 12 de 2014. 
I de 1977); ${ }^{110}$ elaborar reglas de enfrentamiento que determinen las condiciones en las que pueden recurrir a la fuerza armada en el desempeño de su misión; o mecanismos de supervisión y control que permitan tomar medidas para poner fin a las violaciones de estas normas y promover su castigo, como informar a las autoridades de la comisión de cualquier posible infracción. ${ }^{111}$

En caso de que no se adopten o se apliquen adecuadamente estas medidas preventivas, los directivos de estas empresas podrían ser acusados de los crímenes cometidos por las personas a su cargo, pues se podría entender que no ejercieron el control apropiado sobre sus subordinados para prevenir o para impedir la comisión de estos crímenes o para asegurar su persecución. ${ }^{112}$

\section{Consideraciones finales}

La creciente presencia de contratistas privados en los conflictos armados constituye un desafío para la aplicación del derecho internacional humanitario, pues la ambigüedad jurídica en la que llevan a cabo sus actividades les proporciona una impunidad de facto que resulta polémica por los incidentes en los que se han visto envueltos. Frente a esta errónea percepción, se debe reiterar que estas empresas y su personal no operan al margen de la ley. En efecto, el derecho internacional humanitario constituye el marco jurídico adecuado para regular el comportamiento de sus empleados y poner coto a los abusos que están cometiendo en estos escenarios, tal como se deriva de las diferentes iniciativas de regulación internacional que actualmente están en

\footnotetext{
110 Protocolo Adicional a los Convenios de Ginebra del 12 de agosto de 1949 relativo a la protección de las víctimas de los conflictos armados internacionales, del 8 de junio de 1977. 111 En este sentido, ver Lehnardt, “Individual liability...”, op. cit., p. 1028. Un ejemplo de este tipo de medidas lo encontramos en la Directriz del Departamento de Defensa 2311.01E, en la que se establece que "[a]ll military and U.S. civilian employees, contractor personnel, and subcontractors assigned to or accompanying a DoD Component shall report reportable incidents through their chain of command. Contracts shall require contractor employees to report reportable incidents to the commander of the unit they are accompanying or the installation to which they are assigned, or to the Combatant Commander". Department of Defense, Directive 2311.01E, May 9, 2006, DoD Law of War Program, Section 6.3. Asimismo, estas medidas están contenidas en los códigos de conducta de algunas empresas del sector, como Aegis.

112 Así lo ha confirmado con carácter general -no referido a empresas militares y de seguridad privadas- la jurisprudencia de la Corte Penal Internacional en el caso Bemba. Vid. The Prosecutor v. Jean-Pierre Bemba Gombo..., op. cit., pars. 437-441.
} 
marcha. En ellas se insiste en que estas compañías están obligadas a respetar las obligaciones derivadas del ius in bello. Por eso, cuando presten servicios armados o estrechamente vinculados al desarrollo de la acción militar, los contratistas privados estarán sometidos a los estrictos límites que dichas normas imponen, sobre todo en relación con el uso de la fuerza letal o con el trato debido a los detenidos. A tal efecto, deberán tomar las medidas oportunas para que su personal las cumpla, ya que, en caso contrario, incurrirán en responsabilidad individual, que no se circunscribe a los meros ejecutores, sino que también se extiende a los gestores y administradores.

Pero no se debe olvidar que la presencia de estos nuevos actores en los conflictos armados se explica por la tendencia a subcontratar determinados servicios militares o de seguridad que se observa en numerosos Estados, incluidos los más poderosos, ya sea en su territorio, ya sea en sus intervenciones en el extranjero. Por ello, corresponde a los Estados el deber de garantizar el respeto del derecho internacional humanitario por todas las personas que se encuentren bajo su jurisdicción, incluidos los contratistas privados, en consonancia con la obligación contenida en el artículo $1^{\circ}$ común a los Convenios de Ginebra de 1949. Los Estados no pueden así eludir este compromiso encargando la realización de tareas que no deseen llevar a cabo directamente a compañías militares y de seguridad privadas. En consecuencia, el Estado contratante o el Estado en cuyo territorio opera la empresa tendrá que adoptar todas las medidas legislativas o de otro tipo para prevenir y, en su caso, perseguir, cualquier violación grave del derecho internacional humanitario. En caso contrario, incurrirán en responsabilidad internacional.

Desafortunadamente, en la actualidad, el panorama resulta algo decepcionante, pues no se observa entre los Estados que recurren más habitualmente a estas empresas una voluntad real de articular mecanismos de supervisión eficaces para garantizar la rendición de cuentas de los contratistas privados en casos de violaciones graves del derecho internacional humanitario. Así lo ponen de manifiesto las dificultades para la elaboración de un tratado -al margen de las iniciativas de autorregulación que pueden ser útiles, pero insuficientes o ineficaces- que regule sus actividades y clarifique las obligaciones de Estados y empresas; y los obstáculos que han surgido para el enjuiciamiento de los responsables de estas infracciones o la continua contratación de compañías con graves antecedentes de incumplimiento de estas normas. En esta tesitura, el reto al que se enfrenta el derecho internacional humanitario para garantizar su respeto por parte de estas empresas no es tanto la elaboración de nuevas normas, sino lograr que se cumplan las 
ya existentes, eliminando los obstáculos legales -pero, sobre todo, políticosque impiden su aplicación eficaz, a menudo con la complacencia de algunos Estados, que se aprovechan de esta incertidumbre jurídica para eludir sus obligaciones internacionales en la materia.

\section{Referencias bibliográficas}

Andrés Sáenz de Santa María, Paz, "Las dinámicas del derecho internacional en el siglo XXI: acordes y desacordes”, en Martín y Pérez de Nanclares, J. (coord.), Estados y organizaciones internacionales ante las nuevas crisis globales, Iustel, Madrid, 2010, pp. 81-101.

Ballesteros Moya, Vanessa, "Las empresas militares y de seguridad privadas como entidades que ejercen prerrogativas públicas a efectos de la responsabilidad internacional de Estado", Revista Electrónica de Estudios Internacionales, 2013, (25), en http:/ /www.reei.org/index.php/ revista/num 25

Bearpark, Andrew \& Schulz, Sabrina, "The future of the market", in Chesterman, S. \& Lehnardt, Ch. (eds.), From mercenaries to market: the rise and regulation of private military companies, Oxford University Press, Oxford, 2007, pp. 239-250.

Ben Mahfoudh, Haykel, «Acteurs non étatiques et conflits armés non internationaux», in Ben Achour, R. \& Laghmani, S. (dirs.), Acteurs non étatiques et droit international, Pedone, Paris, 2007, pp. 215-241.

Boisson de Chazournes, Laurence \& Condorelli, Luigi, "Common article 1 of the Geneva Conventions revisited: protecting collective interests", International Review of the Red Cross, 2000, 82, (837), pp. 67-87.

Buckland, Benjamin S. \& Burdzy, Anna Marie, Progress and opportunities, five years on: challenges and recommendations for Montreux Document endorsing States, DCAF, Geneva, 2013.

Cameron, Lindsey \& Chetail, Vincent, Privatizing war. Private military and security companies underpublic international law, Cambridge University Press, Cambridge, 2013.

Clapham, Andrew, "Human rights obligations of non-state actors in conflict situations", International Review of the Red Cross, 2006, 88, (863), pp. 491-523.

Cockayne, James, "La reorganización mundial de la violencia legítima: las empresas militares y la cara privada del derecho internacional humanitario", International Review of the Red Cross, 88, (863), pp. 273-308. 
Cockayne, James, "Regulating private military and security companies: the content, negotiation, weaknesses and promise of the Montreux Document", Journal of Conflict \& Security Law, 2009, 13, (3), pp. 393-400.

Cockayne, James \& Mears, Emily Speers, Private military and security companies: a framework for regulation, International Peace Institute, New York, 2009.

Cusumano, Eugenio, "Policy prospects for regulating private military and security companies", in Francioni, F. \& Ronzitti, N. (eds.), War by contract. Human rights, humanitarian law and private contractors, Oxford University Press, Oxford, 2011, pp. 11-36.

David, Eric, «Le droit international humanitaire et les acteurs non étatiques », in College of Europe, La pertinence du droit international humanitaire pour les acteurs non-étatiques. Actes du Colloque de Bruges, 25-26 octobre 2002, College of Europe, Bruges, 2003, pp. 27-40.

David, Eric, Principes de droit des conflits armés, 4e éd., Bruylant, Bruxelles, 2008.

De Nevers, Renée, "The effectiveness of self-regulation by the private military and security industry", Journal of Public Policy, 2010, 30, (2), pp. 219-240.

Dickinson, Laura, "Government for hire: privatizing foreign affairs and the problem of accountability under international law", William and Mary Law Review, 2005, 47, (1), pp. 135-237.

Dickinson, Laura, "Public law values in a privatized world", Yale Journal of International Law, 2006, 31, pp. 383-426.

Doswald-Beck, Louise, "Private military companies under international humanitarian law", in Chesterman \& Lehnardt, From mercenaries to market: the rise and regulation of private military companies, Oxford University Press, Oxford, 2007, pp. 115-138.

Droege, Cordula, "El verdadero Leitmotiv: la prohibición de la tortura y otras formas de malos tratos en el derecho internacional humanitario", International Review of the Red Cross, (867), pp. 217-245.

Engle, Eric, "Corporate Social Responsibility (CSR): market-based remedies for international human rights violations?", Willamette Law Review, 2004, 40, (1), pp. 103-121.

Fenrick, William J., "Article 28. Responsibility of commanders and others superiors", in Triffterer, O. (ed.), Commentary on the Rome Statute of International Criminal court. Observers' notes, article by article, Nomos Verlagsgesellschaft, Baden-Baden, 1999, pp. 515-522.

Fleck, Dieter, "International humanitarian law after September 11: challenges and the need to respond", Yearbook of International Humanitarian Law, 2003, 6, pp. 41-71. 
García Rico, Elena del Mar, "Los conflictos armados del siglo XxI: ¿nuevos conflictos, viejas normas?", en Martín y Pérez de Nanclares, Estados y organizaciones internacionales ante las nuevas crisis globales, Iustel, Madrid, 2010, pp. 511-522.

Gillard, Emanuela-Chiara, «Quand l'entreprise s'en va-t-en guerre: les sociétés militaires et sociétés de sécurité privées et le droit international humanitaire», International Review of the Red Cross, 88, (863), pp. 173-224.

Gómez del Prado, José Luis \& Torroja Mateu, Helena, Hacia la regulación internacional de las empresas militares y de seguridad privadas, Marcial Pons, Madrid, 2011.

Henckaerts, Jean-Marie \& Doswald-Beck, Louise, El derecho internacional humanitario consuetudinario, vol. I, CICR, Buenos Aires, 2007.

Henzelin, Marc, «Les 'raisons de savoir' du supérieur hiérarchique qu'un crime va être commis ou a été commis par un subordonné. Examen de la jurisprudence des Tribunaux pénaux internationaux pour l'exYougoslavie et le Rwanda», in Tavernier, P. (dir.), Actualité de la jurisprudence pénale internationale à l'heure de la mise en place de la Cour pénale internationale, Bruylant, Bruxelles, 2004, pp. 81-125.

Jerbi, Scott, The International Code of Conduct for Private Security Service Providers, Academy Briefing $\mathrm{N}^{\circ}$ 4, Geneva Academy of International Humanitarian Law and Human Rights, August 2013.

Kalshoven, Frits \& Zegveld, Liesbeth, Restricciones en la conducción de la guerra. Introducción al derecho internacional bumanitario, CICR, Ginebra, 2001.

Kincade III, Mathew, "The private military company complex in Central and Southern Africa: the problematic application of international humanitarian law", Washington University Global Studies Law Review, 2013, 12, (1), pp. 205-226.

Laborie Iglesias, Mario, La privatización de la seguridad. Las empresas militares y de seguridad privadas en el entorno estratégico actual, Ministerio de Defensa, Madrid, 2013.

Lapointe, Marie-Ève, «Le droit international humanitaire, à la merci des entreprises militaires et de sécurité privées?», Revue Québécoise de Droit International, 2011, 24, (1), pp. 69-104.

Lehnardt, Chia, "Individual liability of private military personnel under international criminal law", European Journal of International Law, 2008, 19, (5), pp. 1015-1034.

Lirola Delgado, Isabel \& Martín Martínez, Magdalena M., La Corte Penal Internacional. Justicia versus impunidad, Ariel, Madrid, 2001. 
McDonald, Avril, "Ghosts in the machine: some legal issues concerning US military contractors in Iraq", in Schmitt, M. N. \& Pejic, J. (eds.), International law and armed conflict: exploring the faultlines. Essays in honour of Yoram Dinstein, Martinus Nijhoff Publishers, Leiden, 2007, pp. 357-401.

Melzer, Nils, Guia para interpretar la noción de participación directa en las hostilidades según el derecho internacional humanitario, CICR, Ginebra, 2010.

Moodie, Michael, "Conflicts trends in the $21^{\text {st }}$ century", Joint Force Quarterly, 2009, (53), pp. 19-27.

Nerlich, Volker, "Superior responsibility under article 28 ICC Statute. For what exactly is the superior held responsible?", Journal of International Criminal Law, 2007, 5, (3), pp. 665-682.

Paulus, Andreas \& Vashakmadze, Mindia, "Asymmetrical war and the notion of armed conflict - a tentative conceptualization", International Review of the Red Cross, 2009, 91, (873), pp. 95-125.

Pérez González, Manuel, "Las relaciones entre el derecho internacional de los derechos humanos y el derecho internacional humanitario", Cursos Euromediterráneos Bancaja de Derecho Internacional, 1997, I, pp. 315-393.

Pérez González, Manuel, "El artículo $3^{\circ}$ común a los Convenios de Ginebra de 1949 como expresión normativa del 'poder de la humanidad': algunas reflexiones”, en Badía Martí, A. M.; Pigrau Solé, A. \& Olesti Rayo, A. (coords.), Derecho internacionaly comunitario ante los retos de nuestro tiempo. Homenaje a la profesora Victoria Abellán Honrubia, vol. I, Marcial Pons, Madrid, 2009, pp. 485-515.

Pérez González, Manuel, “Principios y 'leyes' de humanidad en situaciones de conflicto. Valor de la cláusula Martens a la luz del derecho internacional humanitario", en Rodríguez-Villasante y Prieto, J. L. \& López Sánchez, J. (coords.), La protección de la dignidad de la persona y el principio de humanidad en el siglo XXI. Estudios de derecho internacional bumanitario, derechos humanos y función policial in memoriam Gonzalo Jar Couselo, Tirant lo Blanch, Valencia, 2012, pp. 115-137.

Pérez-León Acevedo, Juan Pablo, La responsabilidad internacional del individuo por crimenes de guerra, ARA Editores, Lima, 2008.

Pictet, Jean S. (dir.), Commentaire de la Convention de Genève pour l'amélioration du sort des blessés et des malades dans les forces armées en campagne, Comité International de la Croix-Rouge, Genève, 1952.

Pictet, Jean, Desarrollo y principios del derecho internacional humanitario, Instituto Henry Dunant, Ginebra, 1986.

Pons Rafols, Xavier, "Revisitando a Martens: las normas básicas de humanidad en la Comisión de Derechos Humanos", en Salinas de Frías, 
A. \& Vargas Gómez-Urrutia, M. (coords.), Soberania del Estado y derecho internacional. Homenaje al profesor Juan Antonio Carrillo Salcedo, tomo II, Universidad de Córdoba/Universidad de Sevilla/Universidad de Málaga, Sevilla, 2005, pp. 1095-1118.

Pozo Serrano, Pilar, "Las compañías de seguridad privadas como nuevo actor en el ámbito de la paz y la seguridad internacionales: actividades y marco jurídico", en Blanc Altemir, A. (ed.), Elproceso de reforma de las Naciones Unidas. La dimensión institucionaly el mantenimiento de la pazy la seguridad internacionales, Tecnos, Madrid, 2009, pp. 373-395.

Quirico, Ottavio, "The criminal responsibility for private military and security company personnel under international humanitarian law", in Francioni \& Ronzitti, War by contract. Human rights, humanitarian law and private contractors, Oxford University Press, Oxford, 2011, pp. 423-447.

Reinisch, August, "The changing international legal framework for dealing with non-state actors", in Alston, P. (ed.), Non-State actors and buman rights, Oxford University Press, Oxford, 2005, pp. 37-89.

Reydams, Luc, "À la guerre comme à la guerre: patterns of armed conflict, humanitarian law responses and new challenges", International Review of the Red Cross, 2006, 88, (864), pp. 729-756.

Rodríguez-Villasante \& Prieto, José Luis, "La responsabilidad de los superiores jerárquicos militares y no militares a la luz de la legislación nacional del Estado de que se trate y de la experiencia internacional", en Olásolo Alonso, H. \& Cuenca Curbelo, S. (coords.), Perspectiva iberoamericana sobre la justicia penal internacional, vol. I, Tirant lo Blanch, Valencia, 2012, pp. 157-170.

Rosemann, Nils, 'The privatization of human rights violations - Business' impunity or corporate responsibility? The case of human rights abuses and torture in Iraq", Non-State Actors and International Law, 2005, 5, (1), pp. 77-100.

Rosemann, Nils, Code of Conduct: tool for self-regulation for private military and security companies, Occasional Paper No 15, Geneva Centre for Democratic Control of Armed Forces, Geneva, 2008.

Ryngaert, Cedric, "Human rights obligations and armed groups", Revue Belge de Droit International, 2008, 41, (1-2), pp. 355-381.

Schwarzenberger, Georg, "Functions and foundations of the laws of war", Archiv für Rets-und Sozialphilosophie, 1958, 44, (3), pp. 351-369.

Seger, Paul, "The Swiss initiative on private military and security companies", in Odello, M. \& Beruto, G. L. (eds.), Non-State actors and international 
bumanitarian law. Organized armed groups: a challenge for the $21^{\text {st }}$ century, Franco Angeli, Milano, 2010, pp. 119-126.

Sossai, Mirko, "Status of private military and security company personnel in the law of international armed conflict", in Francioni \& Ronzitti, War by contract. Human rights, bumanitarian law and private contractors, Oxford University Press, Oxford, 2011, pp. 197-217.

Thürer, Daniel \& Maclaren, Malcolm, "Military outsourcing as a case study in the accountability and responsibility of power", in Reinisch, A. \& Kriebaum, U. (eds.), The law of international relations. Liber Amicorum Hanspeter Neubold, Eleven Publishing International, Utrech, 2007, pp. 391-413.

Uesseler, Rolf, La guerra como negocio. Cómo las empresas militaresprivadas destruyen la democracia, Belacqva, Barcelona, 2007.

Vetter, Greg R., "Command responsibility of non-military superiors in the International Criminal Court (ICC)", Yale Journal of International Law, 2000, 25, (1), pp. 89-143.

Walker, Clive \& Whyte, Dave, "Contracting out war? Private military companies, law and regulation in the United Kingdom", International and Comparative Law Quarterly, 2005, 54, (3), pp. 651-690.

Werle, Gerhard, Tratado de derecho penal internacional, $2^{a}$ ed., Tirant lo Blanch, Valencia, 2011.

Williamson, Jamie Allan, "Some considerations on command responsibility and criminal liability", International Review of the Red Cross, 2008, 90, (870), pp. 303-317.

Zegveld, Liesbeth, The accountability of armed opposition groups in international law, Cambridge University Press, Cambridge, 2002. 
